\title{
A Combined Satellite-Derived Drought Indicator to Support Humanitarian Aid Organizations
}

\author{
Markus Enenkel ${ }^{1, *}$, Caroline Steiner ${ }^{1}$, Thomas Mistelbauer ${ }^{1}$, Wouter Dorigo ${ }^{1}$, \\ Wolfgang Wagner ${ }^{1}$, Linda See ${ }^{2}$, Clement Atzberger ${ }^{3}$, Stefan Schneider ${ }^{4}$ and Edith Rogenhofer ${ }^{5}$ \\ 1 Department of Geodesy and Geoinformation (GEO), Vienna University of Technology (TU Wien), \\ Vienna 1040, Austria; caroline.steiner@geo.tuwien.ac.at (C.S.); thomas.mistelbauer@geo.tuwien.ac.at (T.M.); \\ wouter.dorigo@geo.tuwien.ac.at (W.D.); wolfgang.wagner@geo.tuwien.ac.at (W.W.) \\ 2 International Institute for Applied Systems Analysis (IIASA), \\ Ecosystems Services and Management (ESM) Group, Laxenburg 2361, Austria; see@iiasa.ac.at \\ 3 Institute of Surveying, Remote Sensing and Land Information, \\ University of Natural Resources and Life Sciences (BOKU), Vienna 1180, Austria; \\ clement.atzberger@boku.ac.at \\ 4 ZAMG, Vienna 1190, Austria; stefan.schneider@zamg.ac.at \\ 5 Doctors without Borders, Médecins Sans Frontières (MSF), Austrian Section, Vienna 1020, Austria; \\ edith.rogenhofer@vienna.msf.org \\ * Correspondence: markus.enenkel@geo.tuwien.ac.at; Tel.: +43-1-58801-12210; Fax: +43-1-58801-12299
}

Academic Editors: Yoshio Inoue and Prasad S. Thenkabail

Received: 14 October 2015; Accepted: 6 April 2016; Published: 20 April 2016

\begin{abstract}
Governments, aid organizations and researchers are struggling with the complexity of detecting and monitoring drought events, which leads to weaknesses regarding the translation of early warnings into action. Embedded in an advanced decision-support framework for Doctors without Borders (Médecins sans Frontières), this study focuses on identifying the added-value of combining different satellite-derived datasets for drought monitoring and forecasting in Ethiopia. The core of the study is the improvement of an existing drought index via methodical adaptations and the integration of various satellite-derived datasets. The resulting Enhanced Combined Drought Index (ECDI) links four input datasets (rainfall, soil moisture, land surface temperature and vegetation status). The respective weight of each input dataset is calculated for every grid point at a spatial resolution of 0.25 degrees (roughly 28 kilometers). In the case of data gaps in one input dataset, the weights are automatically redistributed to other available variables. Ranking the years 1992 to 2014 according to the ECDI-based warning levels allows for the identification of all large-scale drought events in Ethiopia. Our results also indicate a good match between the ECDI-based drought warning levels and reported drought impacts for both the start and the end of the season.
\end{abstract}

Keywords: remote sensing; drought monitoring; drought index; food security

\section{Introduction}

Severe droughts can affect large populations, lead to a long-term threat to people's livelihoods and result in tremendous economic loss. Agricultural droughts, which are the focus of this study, have the potential to cause large-scale crop failure and famine, resulting in severe challenges to governmental and non-governmental aid organizations. The problem with drought management consists of two interconnected elements. On the one hand, neither the detection of drought onset and severity nor the formulation of a common drought definition [1,2] are straightforward. On the other hand, a systemic failure of politics and markets and weaknesses in the transformation of drought early warning information into subsequent action impede efficient humanitarian assistance. In particular in Sub-Saharan Africa, droughts often left regions in a state of chronic poverty [3] and depending 
on external assistance. Although the total number of people that were classified as suffering from chronic hunger decreased globally to 795 million in 2015 (216 million less than 1990/92), mainly due to improvements in Asia, the numbers are still rising on the African continent [4]. While UN FAO [5] state that about 65 percent of Africa's arable land is suffering from reduced soil fertility caused by land degradation, climate change and population growth are predicted to put additional pressure on agricultural systems. These factors are expected to strongly affect local agricultural production $[6,7]$.

Currently, a paradigm change from emergency response to disaster risk reduction and disaster preparedness is supported by a variety of institutions and political frameworks. A prominent example is the Sendai Framework for Disaster Risk Reduction 2015-2030 [8]. The Sendai Framework and the key outcomes of other recent expert meetings [9] explicitly mention "geospatial information technology" and "space-based information" as indispensable sources of information to support decision-making related to natural disasters. This requires in-depth technology transfer between research and application, user-friendly tools that link near-real-time datasets to consistent time series and new ways of coupling drought risk with socio-economic vulnerability. However, these developments are currently hindered by weak links between scientific findings and operational decision-making.

As a consequence, humanitarian aid organizations either trust the judgment of their own staff in the field, who usually concentrate on local phenomena or consult web portals, such as the Famine Early Warning Systems Network (FEWSNET) [10], the UN FAO Global Information and Early Warning System on food and agriculture (GIEWS) [11], the Global Drought Information System (US National Oceanic and Atmospheric Administration), the African Drought and Flood Monitor (Princeton University) [12] or the Humanitarian Early Warning Service (HEWS) of the UN World Food Programme. Hence, relying on a portal whose information is tailored to the specific needs of one specific user or not tailored to user requirements at all can lead to wrong conclusions. FEWSNET, for instance, states in its authorization documents that "... FEWSNET and its Washington DC office personnel will produce support products and activities for AID/Washington offices ... " [13]. The diversity of users makes it is impossible to produce one set of outputs that fits the requirements of all users, e.g., with regard to the selection of products provided, the geographic focus or the timeliness of assessments. Therefore, users tend to consult different portals. However, the maps or reports of these portals may be contradictory, leaving users without any guidance regarding which of the different information sources to trust. In September 2015, for instance, Mozambique was classified as IPC (Integrated Food Security Phase Classification) level one (minimal) and two (stressed) for some southern regions (IPC has five levels). FAO GIEWS classified Mozambique as suffering from "severe localized food insecurity" based on the latest update from July 2015.

However, even if users would rely on state-of-the-art monitoring from a dedicated knowledge portal one uncomfortable fact remains from both the user's and donors' perspective. It is the inherent reluctance to invest in mitigation measures in the face of an early warning that indicates that a situation is "likely" to happen, but not 100 percent certain. In addition, there is currently no standardized way of defining accurate, critical thresholds in the drought early warning indicators that are acceptable for triggering action [14]. At the same time, Kull et al. [15] have proven the effectiveness of disaster risk mitigation compared to emergency response via cost-benefit-analysis, in particular in developing countries. Nevertheless, only 12 percent of the total funding related to disaster management was spent on disaster preparedness activities. Most of the money was used for post-disaster actions, such as emergency response. In addition, countries affected by drought received comparably lower funding for disaster risk reduction than countries that are prone to flood risk or thunderstorms [16].

To overcome the above-mentioned limitations, this study aims at the development of an improved agricultural drought indicator in direct collaboration with Doctors without Borders (Médecins sans Frontières (MSF)). The new drought indicator, the Enhanced Combined Drought Index (ECDI), is based on four independently calculated components that include satellite-derived observations of rainfall, soil moisture, land surface temperature and vegetation vigor. The index design aims at the timely and 
reliable detection of drought events with regard to their spatio-temporal extent and severity. In order to be able to consider drought impacts, which are neglected by most drought monitoring initiatives $[17,18]$, the ECDI is linked to a mobile application. This application allows the consideration of satellite-derived drought risk in relation to the assessment of people's vulnerabilities (e.g., current rates of malnutrition) and coping capacities (e.g., access to drought-resistant seeds). Finally, the ECDI also includes an experimental seasonal forecasting component, whose initial results are discussed briefly in Section 4.4. The entire framework is illustrated in Figure 1, including the drought monitoring component (yellow), the drought forecasting component (green) and the socio-economic component (blue). To evaluate the added-value of the ECDI for operational decision-support, we compare the ECDI-warning levels to two other state-of-the-art drought indices and to local drought reports in Ethiopia.

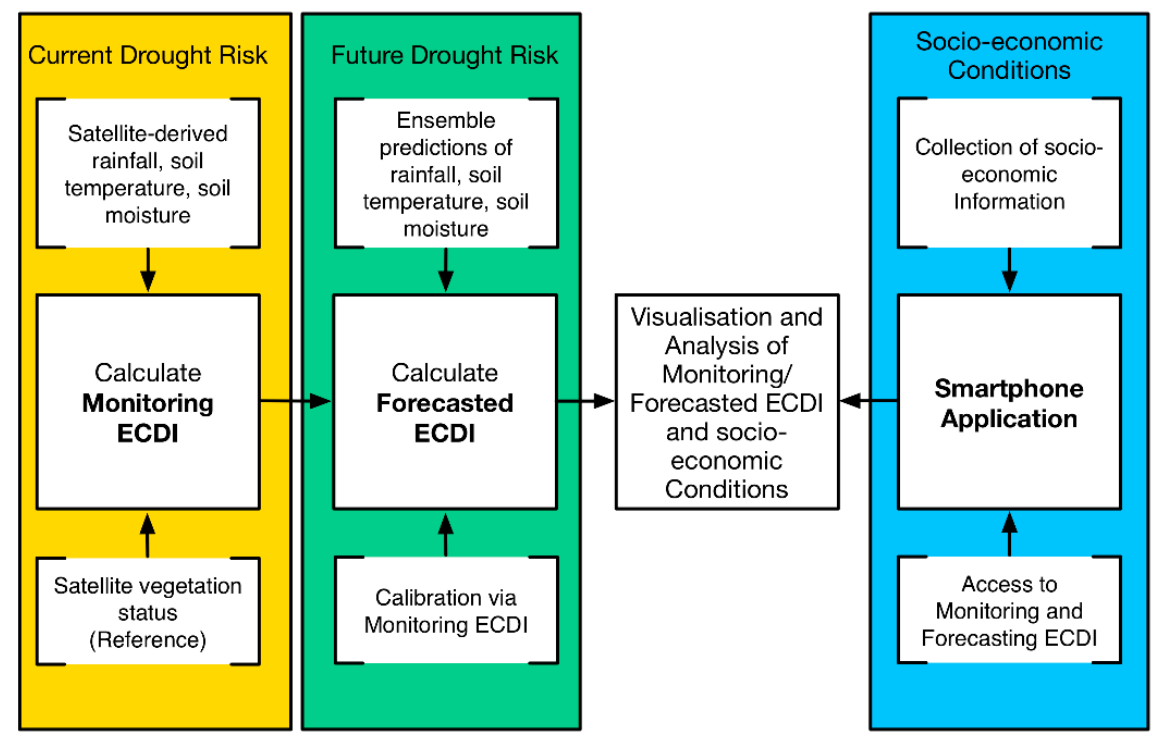

Figure 1. The schematic framework of the SATIDA (Satellite Technologies for Improved Drought-Risk Assessment) research project.

\section{Study Area}

Performance tests of the ECDI are carried out for Ethiopia, which has a total surface of around 1.1 million $\mathrm{km}^{2}$ divided in nine ethnically defined districts. The total population is 84.7 million people [19]. More than 80 percent of the population lives in the rural, higher-elevated areas (Figure 2). Around 80 percent of the population work in the agricultural sector (status 2005), which is responsible for 43 percent of the GDP and 90 percent of exports [20].

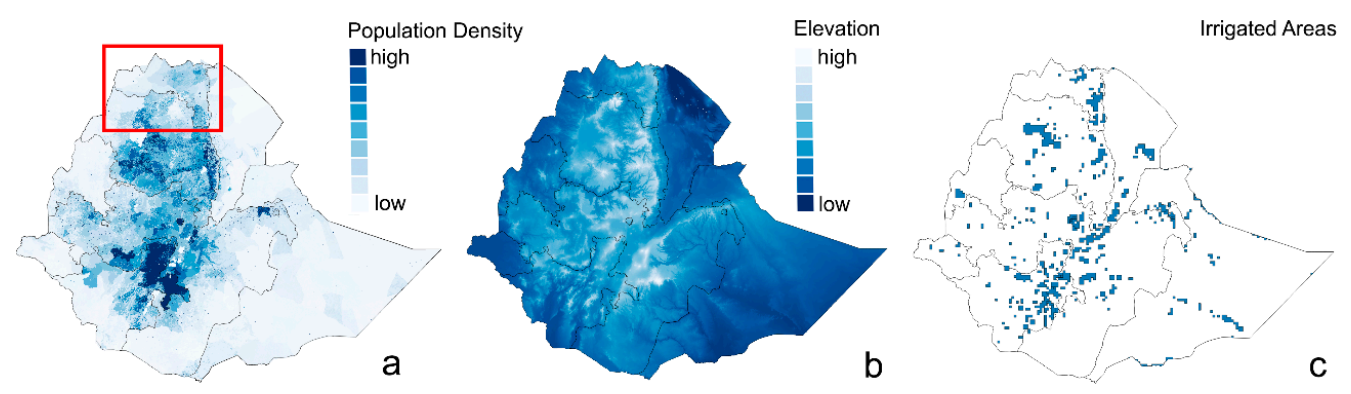

Figure 2. (a) Population density (Worldpop) in Ethiopia, increasing from light to dark blue, the red rectangle highlights the Tigray region in which farmers reported critical moisture deficits in 2007, 2013 and 2014; (b) elevation (CGIAR SRTM 90 m), increasing from dark blue (nearly sea level) to white (more than 4000 meters above sea level); (c) and irrigated areas (global map of irrigation areas, 2013). 
Ethiopia is characterized by a desert climate in the eastern and northeastern parts. The country's lowlands (Figure 2) are mainly hot semiarid in the center-east or tropical in the west [21]. According to the global map of irrigation areas of the UN Food and Agriculture Organization (Version 5.0, 2013) irrigation capacities are very limited throughout the country (Figure 2). Where existing, irrigation systems naturally follow the pattern of population density.

Among 171 countries, the World Risk Report [22] ranks Ethiopia 15th with regard to susceptibility (the likelihood of experiencing negative consequences in an extreme event) from natural disasters. The country's adaptive capacities (long term countermeasures to mitigate impacts) are rated as extraordinarily weak (ranked 12th), resulting in a high overall vulnerability, which comprises susceptibility, coping (short-term) and adaptive capacities. However, with regard to the overall risk assessment Ethiopia only ranks 63rd, because exposure (people and assets that can potentially be affected) towards natural disasters is comparatively low. In contrast, the drought vulnerability index of Naumann et al. [23] classifies Ethiopia as highly vulnerable due to very weak renewable natural capital, weak economic capacity (including food security), weak human/civic resources and a dependency on unreliable rainfall patterns, which are predicted to further depart from the "normal" pattern [24].

In 1984/1985, Ethiopia was struck by a devastating famine that claimed the lives of approximately one million people [25]. At least for some years the prevention of famine ranked high on the political agenda. The most recent large-scale drought in 2011/2012 also affected large parts of Eastern Africa, mainly Somalia and Ethiopia. This time, a specific warning for famine was issued three months in advance [26]. Despite high certainty about the upcoming drought and a high risk of famine the translation of early warning into action on the ground was very slow due to political reasons and financial constraints. Ultimately, 11.5 million people required assistance [27] and aid organizations were struggling with logistical challenges. Since the latter event is well documented we use it in combination with the reports of farmers in Northern Ethiopia (Tigray region) as the benchmark for the ECDI-based warning levels.

\section{Data and Methods}

\subsection{Satellite Data and Drought Indices}

The ECDI uses satellite-derived rainfall, soil moisture, land surface temperature and vegetation status as input datasets. Except for the TAMSAT rainfall product $[28,29]$, which is produced for the African continent only, soil moisture, vegetation status and land surface temperature [30] are available on a global scale. Table S1 summarizes all input variables including the corresponding dataset providers, temporal and spatial coverage and resolution, respectively.

The proposed ECDI is an improvement of the original CDI [31] where soil moisture was not included. The ECDI closes the gap between rainfall and the response of vegetation by introducing a soil moisture component that is retrieved via (passive) microwave remote sensing (Section 3.1.1). In addition, we use a new, noise-corrected, gap-filled and smoothed Normalized Difference Vegetation Index (NDVI) to estimate the plants' health via their photosynthetic activity (Section 3.1.2). Two state-of-the-art drought indices, the self-calibrated Palmer Drought Severity Index [32,33] and the Standardized Precipitation Evapotranspiration Index [34], are presented in (Section 3.1.3) and serve as a "benchmark" for the ECDI-based warning levels.

\subsubsection{Satellite-Derived Soil Moisture}

With regard to drought management AghaKouchak [35] states that measurements of soil moisture possibly improve drought predictability due to higher persistence than precipitation. The studies of Qiu et al. [36] highlight the importance of surface soil moisture for drought monitoring, as well as the role of root-zone soil moisture for the estimation of near-future vegetation anomalies. These and other findings explain the increasing interest in satellite-derived soil moisture products for operational drought monitoring (e.g., El Sharif et al., 2015 [37]; Kumar et al., 2014 [38]). 
However, since satellite-derived soil moisture is a relatively new product most operational remote sensing-based drought indicators rely on rainfall [39], vegetation [40], a combination of rainfall and temperature [32,33,41], rainfall and evapotranspiration [34] or land surface temperature and a surface energy balance model $[42,43]$. Neglecting the soil moisture component in drought monitoring is also critical due to erroneous satellite-derived rainfall observations [44,45]. Rainfall is often not accessible to plants due to runoff or increased rates of evaporation, which will play an increasing role if the impacts of climate change are taken into account [46].

Within the Climate Change Initiative (CCI) of the European Space Agency (ESA), a sophisticated processing chain was developed to merge different products from radar (active microwave sensors) and radiometers (passive sensors) [47-49], exploiting their individual strengths on a global scale. This "ESA CCI soil moisture" dataset covers a period from 1978 to 2014. A recent study of McNally et al. [50] showed that, in combination with NDVI and modeled soil moisture the NDVI provided a "convergence of evidence" for drought monitoring in East Africa. In order to use the CCI soil moisture for operational drought monitoring the processing chain was experimentally adapted for the integration of near-real-time (NRT) observations at TU Wien (Austria). The resulting dataset is generated daily on a regular $0.25^{\circ}$ grid and includes observations from the Advanced Scatterometer (ASCAT) on board MetOP (Meteorological Operational Satellite) and from the Advanced Microwave Scanning Radiometer (AMSR-2) on board the GCOM-W (Global Change Observation Mission-Water) satellite. The ASCAT NRT product is distributed by the European Organisation for the Exploitation of Meteorological Satellites (EUMETSAT), whereas the US National Aeronautics and Space Administration (NASA) and the Japan Aerospace Exploration Agency distribute the AMSR-2 NRT product. By nature, microwave remote sensing of soil moisture is problematic over complex terrain [51], dense vegetation or frozen soils [52]. Due to data gaps prior to 1992, the computation of the ECDI was limited to the period 1992 to present.

\subsubsection{Advanced NDVI Products}

The NDVI is widely used to map vegetation conditions on a global scale [53], to estimate crop yields [54], to monitor agricultural land [55] and for informing index-based (agricultural) insurances [56]. In particular in Ethiopia the NDVI was also successfully used to predict vegetation stress during the growing season 1-3 months ahead [57]. The NDVI combines information from red and near-infrared spectral channels to highlight the greenness information. It is produced as an eight-day Maximum-Value-Composite (MVC) product from MODIS (NASA's Moderate-resolution Imaging Spectroradiometer) AQUA and TERRA satellites at $250 \mathrm{~m}$ spatial resolution. Data are available free of charge on a global scale.

Numerous investigations have described the relationships between the NDVI and climatic variables such as rainfall, land surface temperature or soil moisture, depending on land cover or soil types e.g., in Africa [58-61] or in the United States [62-64]. Studies that focus on the relationship between satellite-derived soil moisture and vegetation, such as the one carried out by Nandintsetseg [65] in Mongolia or by Zribi et al. [66] in Tunisia, on the other hand, are rather scarce.

The NDVI is inherently affected by perturbing factors such as (undetected) clouds and poor atmospheric conditions (e.g., aerosols). Therefore, data cleaning is necessary [67,68]. The Institute of Surveying, Remote Sensing and Land Information (IVFL) at the Vienna University of Natural Resources and Life Sciences (BOKU) developed a near-real-time (NRT) smoothing algorithm based on the Whittaker smoother [69,70]. The smoother filters time series of NDVI observations taking available MODIS quality flags into account. The processing is performed every Saturday to deliver NDVI "Monday-images" with a seven-day updating interval [71,72]. The filtered images are not only produced for the current week ( $\mathrm{t})$, but also for the past 13 weeks $(\mathrm{t}-13)$. The data produced for week $\mathrm{t}-13$ serve as reference observations for deriving information about uncertainty (through hindcast analysis) for the NRT products. As new observations become available weekly, the MODIS data are re-filtered every weekend to keep the time series updated and internally consistent. Every NDVI pixel contains 
information about the (modeled) uncertainty range. The performance of the Whittaker smoother was assessed over South America [73] and India [67] and is operationally used by Kenya's National Drought Monitoring Authority (NDMA) for the release of drought contingency funds (DCF) [74].

\subsubsection{Benchmark Drought Indices}

To validate the performance of the ECDI-based warning levels we use two of the most widely used drought indices for comparison:

- $\quad$ the self-calibrated Palmer Drought Severity Index (scPDSI); and

- $\quad$ the Standardized Precipitation Evapotranspiration Index (SPEI).

The scPDSI [32,33] is calculated based on rainfall and temperature from the University of East Anglia's Climate Research Unit (CRU). CRU Version 3.21 is derived from more than 4000 weather station records on a $0.5^{\circ} \times 0.5^{\circ}$ grid. The CRU developers highlight that the final output datasets are not strictly homogeneous, although most input datasets were homogenized. Based on the concept of calculating water supply and demand via a water balance model the PDSI tries to provide standardized soil moisture conditions. In contrast to the original PDSI the scPDSI replaces empirically-derived constants with dynamically calculated values. The CRU scPDSI is provided by the Royal Netherlands Meteorological Institute's (KNMI) Global Climate Explorer.

The SPEI was developed in 2010 by Vicente-Serrano [34] to extend the basic concept of the Standardized Precipitation Index [39] via a temperature component. The adaptation was motivated by that fact that increased rates of evapotranspiration cause additional stress to net primary production, promote tree mortality and the risk of forest fires. Just like the scPDSI, the SPEI is calculated at monthly time steps on a $0.5^{\circ} \times 0.5^{\circ}$ grid. It uses the difference between precipitation and potential evapotranspiration (calculated based on the Thornthwaite equation), which can be calculated at different time scales (1-48 months). The SPEI is available from 1955 to the present and is based on mean temperature data from the NOAA NCEP CPC GHCN_CAMS gridded dataset and rainfall from the Global Precipitation Climatology Centre. The latter dataset is interpolated from a spatial resolution of $1^{\circ}$ to $0.5^{\circ}$. The SPEI is updated during the first days of each month and is available at: http://sac.csic.es/spei.

\subsection{Methods}

The following section describes the ECDI algorithm and its implementation through POETS (Python Open Earth Observation Tools) [75] and PYTESMO (Python Toolbox for the Evaluation of Soil Moisture Observations). In addition to the on-the-fly computation of the ECDI and the warning levels, POETS routinely calculates anomalies for all variables based on the entire available climatology to capture short-term extremes.

The ECDI is based on a modified version of the Combined Drought Index (CDI) that was originally developed by the UN FAO Somalia Water and Land Information Management (SWALIM) team [31] to link anomalies of in-situ measurements (rainfall, temperature) and the NDVI. The proposed new method replaces all in-situ observations with state-of-the-art satellite-derived datasets and adds a soil moisture component. Since the original CDI requested users to choose the weight of each component, sometimes leading to confusion among users, we propose a method that distributes the weights automatically for each grid point. The entire ECDI source code is available on a public Github repository at: https://github.com/tmistelbauer/poets4SATIDA/blob/master/poets/cdi.py.

\subsubsection{Computation of the Monitoring ECDI}

The ECDI is calculated on a regular latitude-longitude grid at decadal (10-daily) time steps. Note that we use decade and decadal in this paper to denote a 10-day time step. All input datasets are resampled to a spatial resolution of $0.25^{\circ}$, corresponding to soil moisture as the input dataset with 
the lowest spatial resolution. Equation (1) illustrates the calculation of one ECDI component, the Precipitation Drought Index (PDI). All other components are calculated in a similar way.

$$
P D I_{y, d}=\frac{\sum_{j=0}^{I P-1} P_{y,(d-j)}^{*}}{\frac{1}{n} \sum_{k=1}^{n}\left[\sum_{j=0}^{I P-1} P_{(d-j), k}^{*}\right]} * \sqrt{\frac{\left(R L^{*}\right) P_{d, y}^{*}}{\frac{1}{n} \sum_{k=1}^{n}\left(R L^{*}\right) P_{d, k}^{*}}}
$$

PDI is the Precipitation Drought Index (an individual index is calculated for precipitation, land surface temperature and soil moisture)

$\mathrm{P}^{*} \quad$ is the decadal precipitation average

$\mathrm{RL}^{*}\left(\mathrm{P}^{*}\right) \quad$ maximum number of successive decades below long term average rainfall in the interest period (run-length)

IP interest period (longer IPs detect more severe drought events)

$\mathrm{RL}^{*} \quad$ is the Run Length parameter

$\mathrm{n} \quad$ number of years with data

$\mathrm{j} \quad$ summation running parameter covering the interest period (IP)

$\mathrm{k} \quad$ summation running parameter covering the years where data are available

d time unit (decade or month)

y year

The basic principle of the ECDI algorithm is to relate the average values of accumulated rainfall, soil moisture, land surface temperature and vegetation health for one interest period (IP) to the long term mean of this IP (left part of Equation (1)) and the number of subsequent decades representing anomalous conditions in this to the corresponding long-term mean in this IP (right part of Equation (1)). The IP is flexible and defines to what extent past observations are considered. The current version runs on an IP of 18 decades, corresponding to the six-months Standardized Precipitation Evapotranspiration Index [34]. In a simplified form this index can be expressed as (Equation (2)):

$$
P D I=\frac{\begin{array}{c}
\text { Actual average } \\
\text { for IP }
\end{array}}{\begin{array}{c}
\text { Long term average } \\
\text { for IP }
\end{array}} \times \sqrt{\frac{\begin{array}{c}
\text { Actual length of continuous } \\
\text { deficit or excess in the IP }
\end{array}}{\begin{array}{c}
\text { Long term average of of continuous } \\
\text { deficit or excess in the IP }
\end{array}}}
$$

PDI is the Precipitation Drought Index

IP interest period

The individual indices for land surface temperature, precipitation and soil moisture are calculated similarly. Deficits in precipitation, soil moisture and vegetation health indicate drought conditions, as well as abnormally high land surface temperatures. Balint and Mutua [31,76] recommend modifying the raw time series of temperature and precipitation as well as the run length to adjust the range of all variables and to avoid a division by zero (Equation (3)). In addition, the temperature and the run length parameter, which counts the successive decades with above normal (temperature) or below normal (rainfall and soil moisture) conditions, are inverted:

$$
\begin{gathered}
T^{*}=\left(T_{\max }+1\right)-T \\
P^{*}=P+1 \\
R L^{*}=\left(R L_{\max }+1\right)-R L
\end{gathered}
$$

$\mathrm{T}^{*} \quad$ is modified Temperature

$P^{*} \quad$ is modified precipitation

$\mathrm{RL}^{*} \quad$ is s modified run length 
All individual indices differ in range. To improve their interpretability and visual comparability we introduce a simple scaling factor. Equation (4) applies the scaling factor to each individual index, in this case the PDI:

$$
P D I_{\text {scaled }}=\left(P D I-P D I_{\min }\right) /\left(P D I_{\max }-P D I_{\min }\right)
$$

$\mathrm{PDI}_{\text {scaled }}$ is the new scaled value

$\mathrm{PDI}_{\text {min }}$ is the minimum value of the decade compared to all decades available

$\mathrm{PDI}_{\max }$ is the maximum value of the decades compared to all decades available

\subsubsection{Adjustment of Weights}

The NDVI is a valuable indicator for agricultural drought in Ethiopia [77], but also often a relatively late indicator of vegetation stress. As a result, the weight of each individual index is automatically calculated with respect to its capability to reflect the future vegetation status (NDVI). The weight of every individual index is calculated for each grid point and multiplied by the respective individual index to calculate the ECDI (Equation (5)). The sum of all weights per decade is one.

$$
E C D I=\sum_{i=1}^{n} w_{i} * D I_{i}
$$

ECDI Enhanced Combined Drought Index

w Weight for each individual drought index (e.g., rainfall)

DI Individual drought index

$\mathrm{n} \quad$ number of drought indices used to calculate the CDI

i running parameter covering the number of drought indices

As a first step, all individual indices for rainfall, soil moisture and temperature are correlated with the individual index of the vegetation status via Pearson's correlation coefficient (R). This way a de-seasonalized agreement can be calculated. As illustrated in Figure 3, the weights are distributed according to the quality of the correlation and the time step at which the highest correlations are observed (Equation (6)).

$$
w_{i}=\frac{\frac{\operatorname{lag}_{i}^{*}}{\sum_{j=1}^{n} \operatorname{lag}_{j}^{*}}+\frac{\operatorname{corr}_{i}^{*}}{\sum_{j=1}^{n} \operatorname{corr}_{j}^{*}}}{2}
$$

$\begin{array}{ll}\text { w } & \text { weight for the respective drought index } \\ \text { lag* } & \text { modified time lag for the respective parameter } \\ \text { corr* } & \text { modified correlation coefficient for the respective parameter } \\ \text { i } & \text { index for the respective parameter/drought index } \\ \text { j } & \text { running parameter covering all parameters used for the ECDI calculation } \\ n & \text { number of individual drought indices used for the ECDI calculation }\end{array}$

If, for instance, the soil moisture individual index has a comparable correlation coefficient to rainfall, but the rainfall individual index indicates the future vegetation status earlier, then the latter is assigned a higher weight. If no data are available for one individual index at one grid point, then the weight is automatically redistributed amongst the remaining indices. Figure 4 illustrates the weight distribution for one component of the ECDI (soil moisture). Based on a combination of time lag and corresponding correlation, the soil moisture component receives an average weight of 34.8 percent for Ethiopia. 


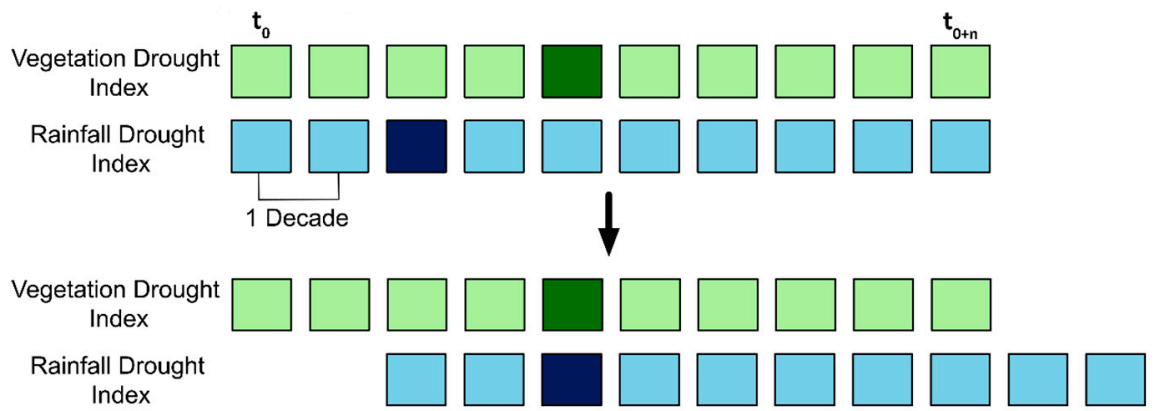

Figure 3. Analysis and exploitation of the time lag relationship. Every square represents a measurement for one decade. In this example, shifting the time series of the rainfall individual index two time steps to the right results in the highest correlation with the individual index representing the vegetation status (dark green and dark blue squares). In combination with the ability of one dataset to "predict" the vegetation status, the quality of the correlation defines the weight of the ECDI's precipitation component in the overall index.

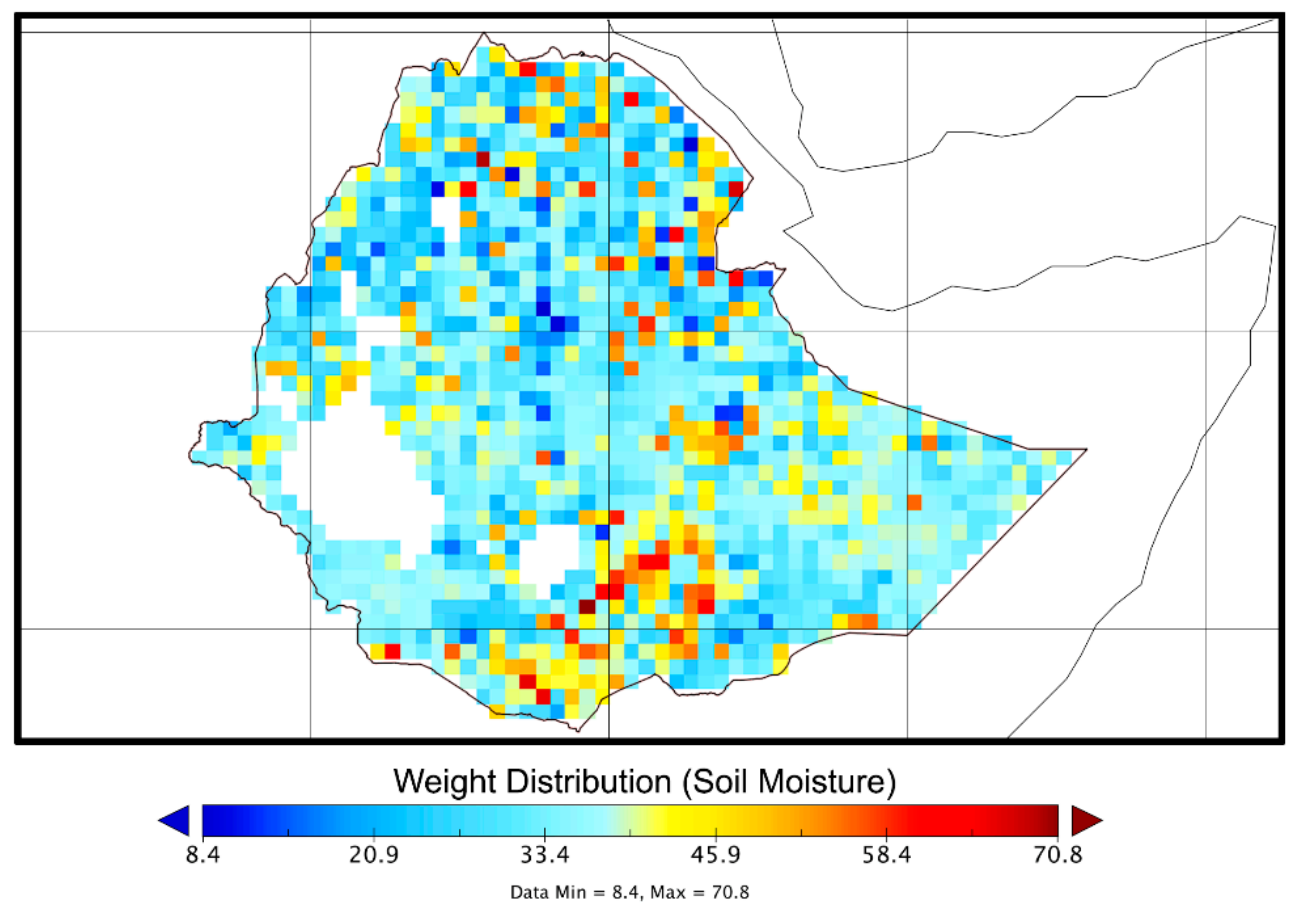

Figure 4. Weight Distribution for the Soil Moisture Drought Index. The masking is related to vegetation density and complex topography. The average weight of the soil moisture component is $34.8 \%$.

\subsubsection{Drought Risk Warning Levels}

The ECDI-based drought risk warning levels (WL) are calculated as follows (Equation (7)):

$$
W L=\frac{\text { Current decadal ECDI Value - Average ECDI Value per Decade }}{\text { Standard Deviation of the decadal ECDI value }}
$$

Table 1 compares the ECDI-based drought risk warning levels to the MSF food security warning levels. The warning levels are calculated as continuous values and grouped in four categories. Normal drought risk conditions are defined up to a warning level value of 0.5 , mild drought risk from 0.5 to 1.5 , severe drought risk from 1.5 to 2.5 and extreme drought risk $>2.5$. 
Table 1. Comparison of MSF food security warning levels and ECDI warning levels.

\begin{tabular}{cccccc}
\hline $\begin{array}{c}\text { Food Security } \\
\text { Level }\end{array}$ & $\begin{array}{c}\text { Generally } \\
\text { Food Secure }\end{array}$ & $\begin{array}{c}\text { Borderline Food } \\
\text { Insecure }\end{array}$ & $\begin{array}{c}\text { Acute Food } \\
\text { Crisis }\end{array}$ & $\begin{array}{c}\text { Food/Humanitarian } \\
\text { Emergency }\end{array}$ & $\begin{array}{c}\text { Famine/Humanitarian } \\
\text { Catastrophe }\end{array}$ \\
\hline $\begin{array}{c}\text { Sample } \\
\text { Parameter } \\
\text { (Food Access) }\end{array}$ & $\begin{array}{c}\text { Adequate } \\
\text { and stable }\end{array}$ & $\begin{array}{c}\text { Borderline } \\
\text { adequate/seasonal } \\
\text { Variations }\end{array}$ & $\begin{array}{c}\text { foobor, } \\
\text { cash) to ensure } \\
\text { food access }\end{array}$ & $\begin{array}{c}\text { Severe lack of } \\
\text { sources; unable to } \\
\text { meet food needs }\end{array}$ & $\begin{array}{c}\text { Extreme lack of } \\
\text { sources, starvation }\end{array}$ \\
\hline $\begin{array}{c}\text { Drought Risk } \\
\text { Level }\end{array}$ & \multicolumn{2}{c|}{ Normal Conditions } & $\begin{array}{c}\text { Increased } \\
\text { Drought Risk }\end{array}$ & $\begin{array}{c}\text { Severe Drought } \\
\text { Risk }\end{array}$ & Extreme Drought Risk \\
\hline $\begin{array}{c}\text { ECDI Warning } \\
\text { Level }\end{array}$ & $<-0.5$ & -0.5 to -1.5 & -1.5 to -2.5 & $>-2.5$ STDV \\
\hline
\end{tabular}

\subsubsection{Computation of the Forecasted ECDI}

The fact that atmospheric processes are chaotic means that small changes in the initial conditions or the forecasting model itself can cause non-linear growths of error. As a consequence, seasonal drought forecasting is even more challenging than weather prediction. Hence, the UK Met Office [78] states that current long-range forecasts are useful to assess the likelihood and potential risk of future events, but not as the basis for definitive warnings. Nevertheless, long-range predictions are a priority to aid organizations, such as MSF, with regard to their operational planning. The following method to calculate a forecasted ECDI is presented as an experimental set-up.

The seasonal forecasting system of the European Centre for Medium Range Weather Forecasting (ECMWF) follows a probabilistic approach. The term "probabilistic" is a reminder to the user that there is always an uncertainty in the forecast, which should be considered, computed and taken into account when using the forecast. The forecasting system consists of 51 (15 for re-forecasts 1981-2010) ensemble members, which are possible realizations of future atmospheric conditions. Forecasts are provided on a global $0.7^{\circ}$ grid every month with a forecast range of up to seven months [79]. Individual model runs and ensemble systems are subject to biases and dispersion errors [80]. Therefore, it is important to calibrate all seasonal predictions for regional conditions. As one of the main requirements of the forecasted ECDI is the temporal homogeneity with respect to the monitoring ECDI, the method of choice is a cumulative distribution function (CDF) matching approach [81], which removes the model bias with reference to the satellite observations.

The seasonal forecasts provided by the ECMWF include a rainfall and a soil moisture component, but they lack a parameter that is directly comparable to the ECDI's land surface (soil skin) temperature. However, it provides air temperature at $2 \mathrm{~m}$ above ground. Despite the fact that soil skin temperature has larger diurnal amplitude and shows larger extreme values, the $2 \mathrm{~m}$ air temperature is a suitable first estimate, as these daily signals are mostly straightened out by averaging over the decades.

Figure 5 offers a schematic illustration of how the ECDI processing chain is fed with seasonal ensemble forecasts of rainfall, temperature and soil moisture. The above-mentioned CDF matching is performed for all three modeled datasets separately. The coarse spatial model resolution is matched with the resolution of the satellite observations $\left(0.25^{\circ}\right)$ via a nearest neighbor search. This way we avoid modifying the model data via an interpolation/resampling scheme. Only the observation-based ECDI until the present decade is used. After a transition period during which both observed and modeled data are used, the ECDI is entirely calculated based on the 15 ensemble forecasts for all 21 decades. To combine the predictions of rainfall, temperature and soil moisture into one forecasted ECDI, every input ensemble member is assigned the weight that has been calculated to develop the monitoring ECDI. For every forecasted decade and grid point, the minimum, maximum, $25 \%$ and $75 \%$ quantile and the median of the 15 ensemble ECDI forecasts are computed and stored. Based on these values the warning levels can be computed for the forecasted ECDI. 


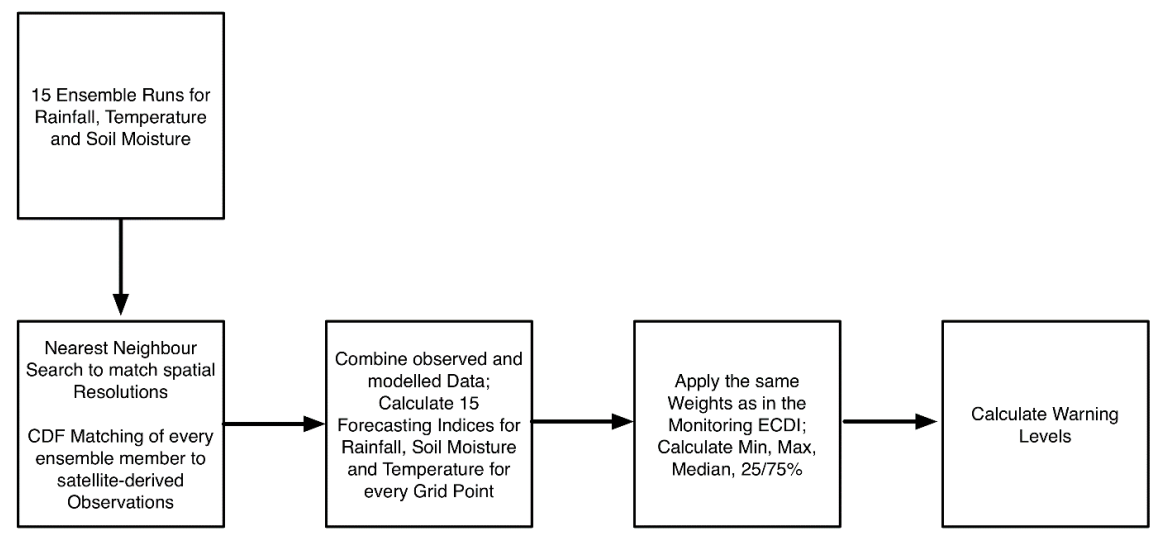

Figure 5. Flowchart illustrating the main steps in generating the forecasting component of the ECDI.

\subsection{Comparison and Validation}

Databases such as the International Disaster Database (www.emdat.be) offer limited and often incomplete records of drought events. Information is only provided annually and on country level, resulting in nine recorded drought events in Ethiopia between 1992 and 2015. According to EmDat, these events (1997-1999, 2003, 2005, 2008-2009, and 2011-2012) affected nearly 40 million people in total with a minimum in 1997 (986,000 people) and the maximum in 2003 (12.6 million people). Therefore, we focus on three complementary strategies:

- We analyze the frequency of drought risk warning levels for each grid point and rank years according to the annual distribution of warning levels (Section 4.1).

- We compare the ECDI-based drought risk warning levels to other (benchmark) drought monitoring indices (SPEI and scPDSI; Section 3.1.3), which are updated monthly. For this purpose, we resample the decadal warning levels to a monthly temporal resolution. Differences in spatial resolution are overcome via a nearest neighbor search. Afterwards, we analyze the agreement between the warning levels and the SPEI as well between the SPEI and the scPDSI (Section 4.2).

- We validate the time series of all ECDI input variables, the corresponding climatology-based anomalies and the ECDI-based warning levels via reports of farmers in the Tigray region (Section 4.3). The farmers had reported moisture deficiencies during the start of season (SOS) in 2007, 2013, 2014 and 2015 which delayed the sowing/germination, and during the end of season (EOS) in 2007, which prohibited the development of fruits. All data were provided by the International Research Institute for Climate and Society (Columbia University).

The severe 2011 drought event is used as an additional benchmark. It is well documented by international reports with regard to spatial and temporal extent.

\section{Results and Discussion}

\subsection{Ranking Drought Years according to ECDI Warning Levels}

Analyzing all 820 decades from January 1992 to March 2015 (17 decades are required to calculate the first value) reveals that grid points in Ethiopia are on average 71 percent of the time classified as "normal" drought risk level, 22 percent in "mild" drought risk, six percent in "severe" drought risk and less than one percent in "extreme" drought risk. While the 2008-09 and 2011-12 events in Figure 6 are directly captured by the annual drought level frequency, the 1997 and 2003 events follow at least one year of even higher levels of drought risk. There is limited documentation about the drought events in 2000 and 2001, mainly due to the fact that the drought did not result in a major famine. However, according to Reliefweb [81] the delay of the Belg rains from March to April 2000 affected the 
food security of around eight million people in the south and southeast. Famine could be prevented by international food assistance. Also in 2001, international aid organizations mention drought as the main reason for internal displacement and major food insecurity, affecting 6 to 7.5 million people [82]. Since the ECDI warning levels detect the highest drought level frequency in 2002, but there was no drought event listed in the EMDAT-database, we continued searching for alternative sources of information. According to the UN Food and Agriculture Organization [83], both rainy seasons had failed in 2002 and 70 percent of the maize and sorghum crops were destroyed. Critical food and water shortages affected 12 to 15 million people [84]. The ECDI-based warning levels reflect the ENSO (El Niño-Southern Oscillation)-related 2002 event by showing that less than half of all decades (2002) were in "normal" drought risk conditions. Also in 2009, large areas were affected by a drought event that the UN Food and Agriculture Organization [85] linked to a moderate El Niño. In several regions in Central/Eastern Ethiopia, more than 85 percent of the cropland suffered from the impact of the drought. In the case of the 2009 event, ECDI-based warning levels show only 57 percent of all decades in normal conditions.

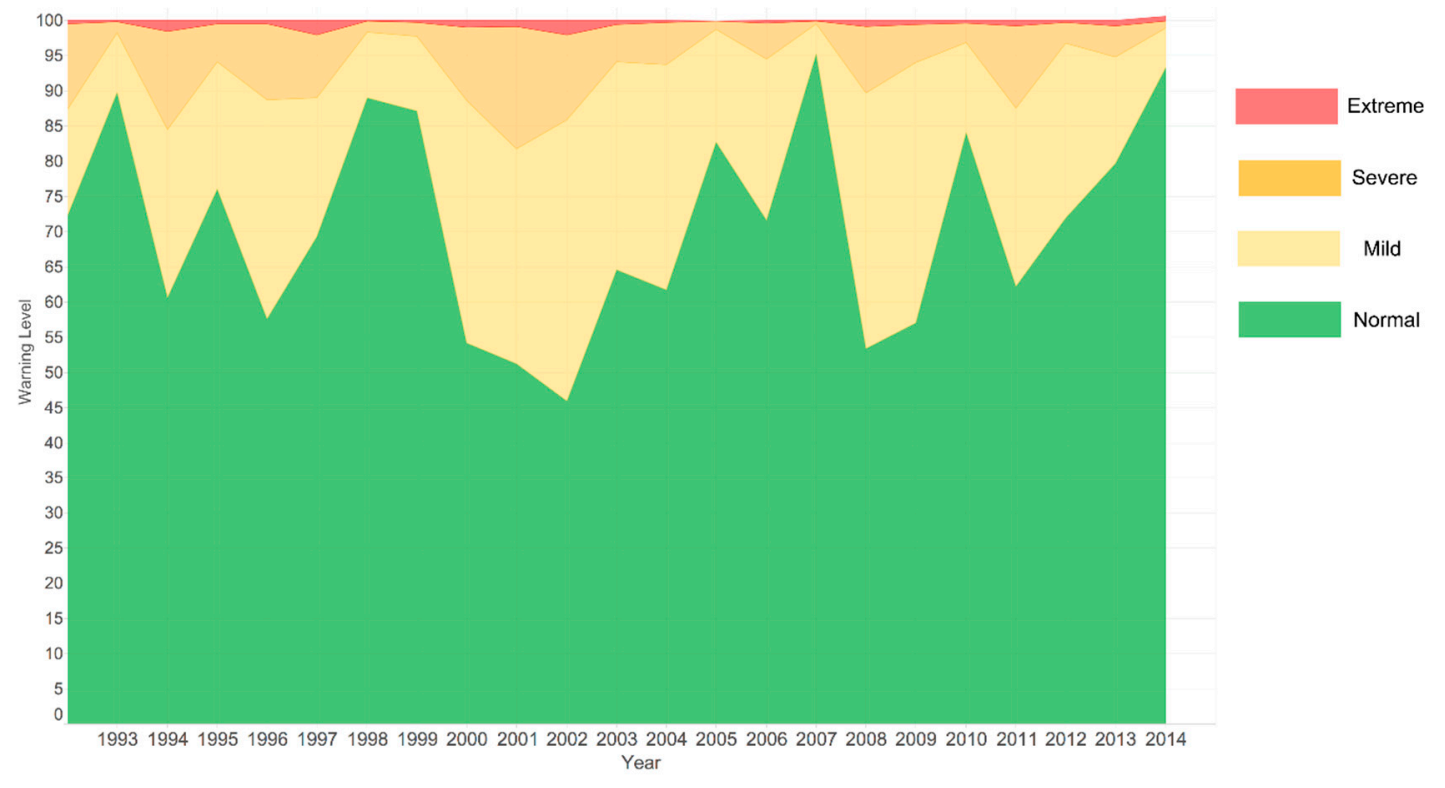

Figure 6. Ranking of Years from 1992 to 2014 according to ECDI Warning Levels.

\subsection{Large-Scale Comparison to SPEI and sc-PDSI}

To understand the temporal and spatial behavior of the ECDI-based warning levels, we calculated the Pearson's correlation coefficient for Ethiopia for all possible index combinations:

- $\quad$ ScPDSI vs. SPEI (1992 to 2015);

- $\quad$ ECDI-based warning levels vs. scPDSI (1992 to 2012); and

- $\quad$ ECDI-based warning levels vs. SPEI (1992 to 2015).

It should be noted that a negative correlation between the ECDI warning levels and the other two drought indicators must be interpreted as a positive agreement, because lower SPEI and scPDSI values correspond to higher warning levels. In general, we observed a low correlation for all combinations. However, throughout Ethiopia and for all seasons the correlation between the satellite-derived ECDI warning levels and the SPEI is far higher than between the ECDI warning levels and the scPDSI (Table 2). Overall, we observe the highest (negative) correlation $(R=-0.4)$ for the ECDI warning levels and the SPEI during the winter season (January to March). We also identify slight differences in the correlation of the indicators with respect to the Belg rainy season (March to May), which is the main rainfall period for the southern and eastern agricultural areas and therefore critical 
for food security, and the Kirempt season (June to September). Considering only the Belg season, the correlation between the ECDI warning levels and the SPEI decreases to $R=-0.31$ and to $R=-0.21$ when only the Kirempt rainy season is considered. The correlation between SPEI and scPDSI does not change from the winter to the Belg season $(R=0.34)$, but also decreases during the Kirempt season $(R=0.24)$. Looking at the spatial patterns throughout the year, the agreement between the scPDSI and the SPEI (average annual $R=0.28$; Figure 7) is comparable to the agreement of the ECDI warning levels and the SPEI (average annual $R=-0.27$; Figure 8). As illustrated in Figure 9, there is virtually no agreement between the ECDI warning levels and the scPDSI (average $R=-0.08$ ).

Table 2. Correlation for all Index Combinations and for all Grid Points in Ethiopia.

\begin{tabular}{ccc}
\hline Indices & Period & Average Pearson's R \\
\hline scPDSI-SPEI & January-December & 0.28 \\
ECDI WL-scPDSI & January-December & -0.09 \\
ECDI WL-SPEI & January-December & -0.27 \\
scPDSI-SPEI & January-March & 0.34 \\
ECDI WL-scPDSI & January-March & -0.21 \\
ECDI WL-SPEI & January-March & -0.40 \\
scPDSI-SPEI & March-May (Belg season) & 0.34 \\
ECDI WL-scPDSI & March-May (Belg season) & -0.1 \\
ECDI WL-SPEI & March-May (Belg season) & -0.31 \\
scPDSI-SPEI & June-September (Kirempt season) & 0.24 \\
ECDI WL-scPDSI & June-September (Kirempt season) & -0.03 \\
ECDI WL-SPEI & June-September (Kirempt season) & -0.21 \\
scPDSI-SPEI & October-December & 0.25 \\
ECDI WL-scPDSI & October-December & -0.08 \\
ECDI WL-SPEI & October-December & -0.23 \\
\hline
\end{tabular}

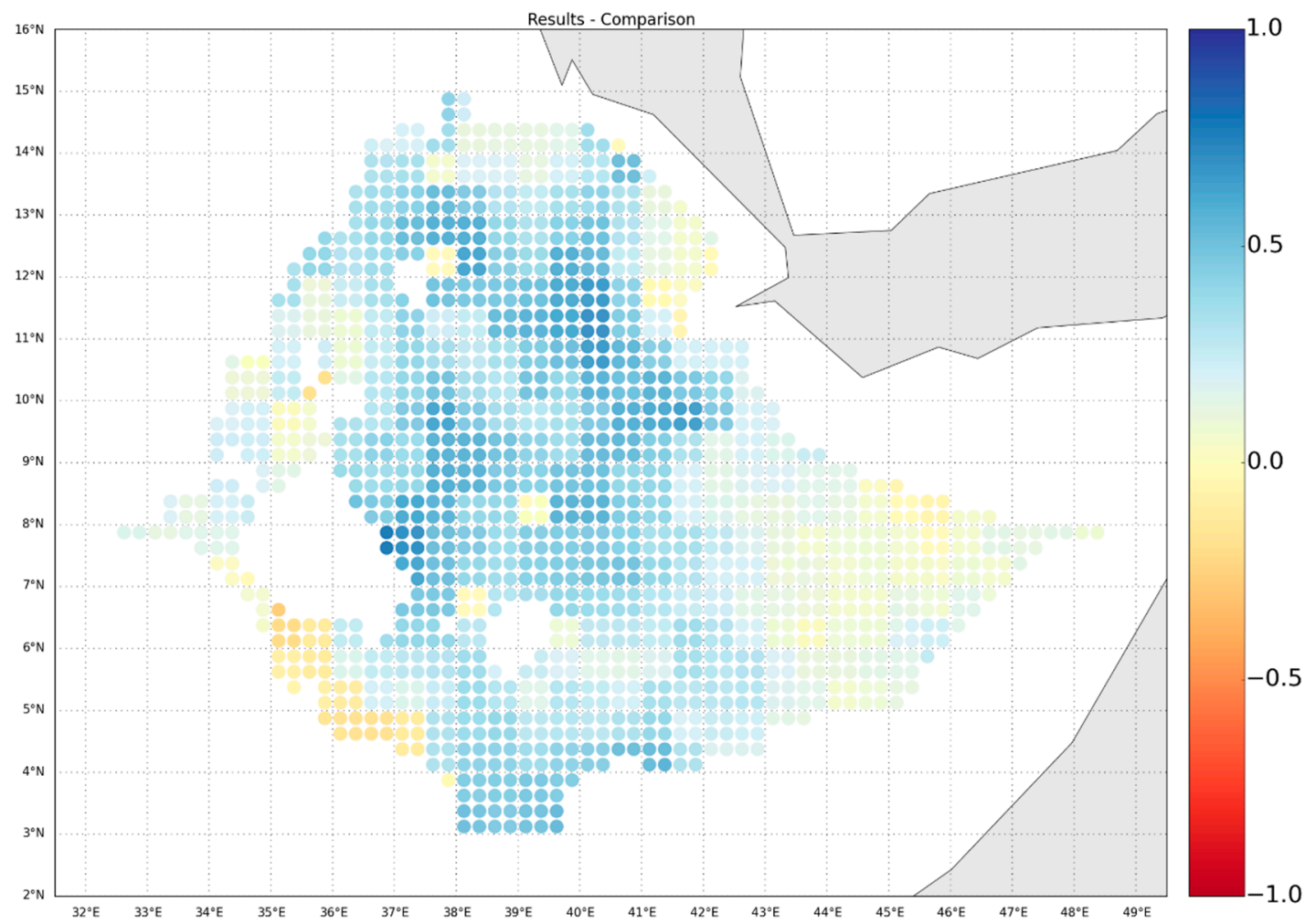

Figure 7. Comparison of SPEI and scPDSI from 1992 to 2012: average Pearson's R: 0.28, and average Stdv: 0.18 . Regions with dense vegetation or complex topography and lakes are masked. 


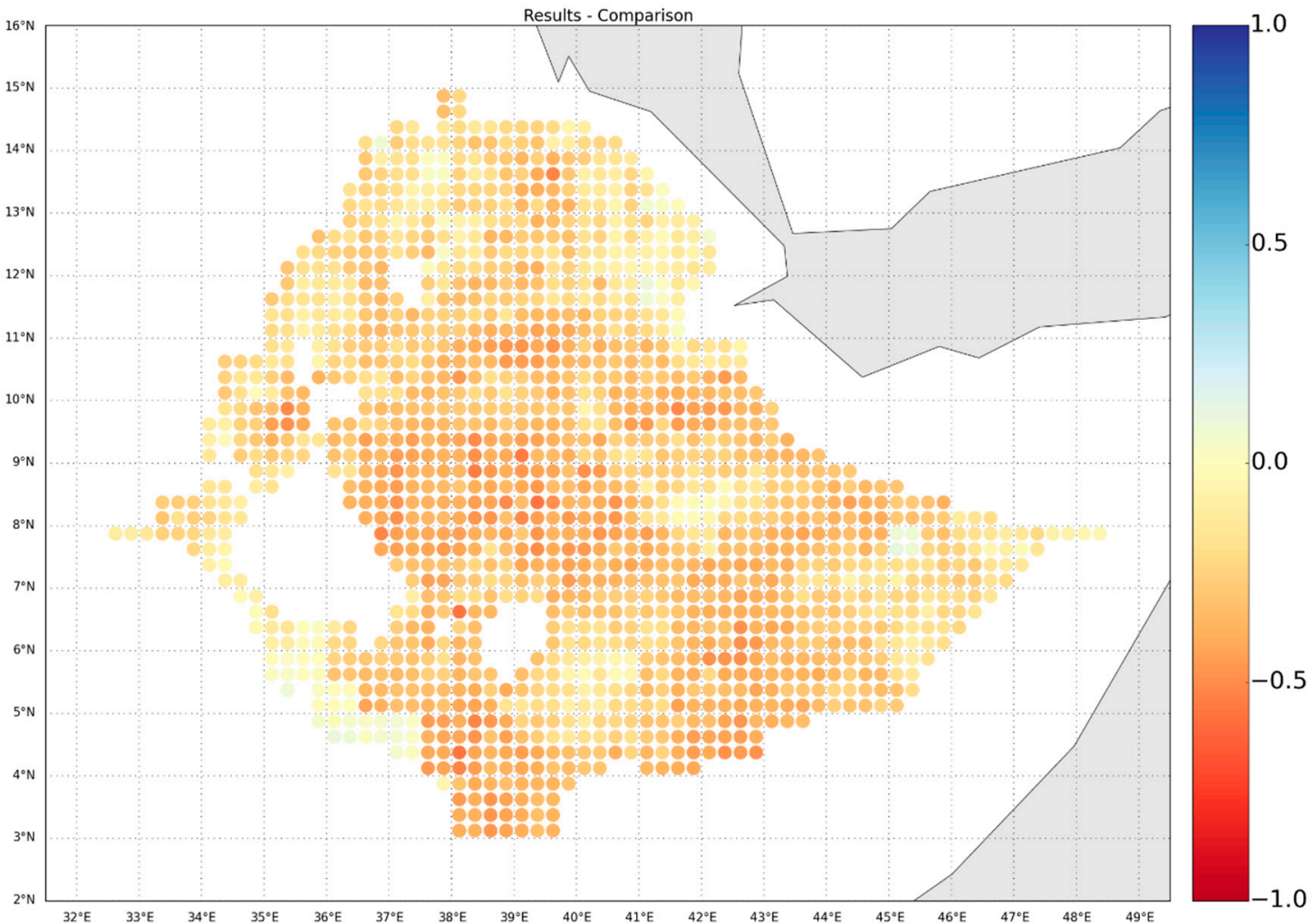

Figure 8. Comparison of ECDI warning levels and SPEI for 1992-2015: average Pearson's R: -0.26, and average Stdv: 0.12. Regions with dense vegetation or complex topography and lakes are masked.

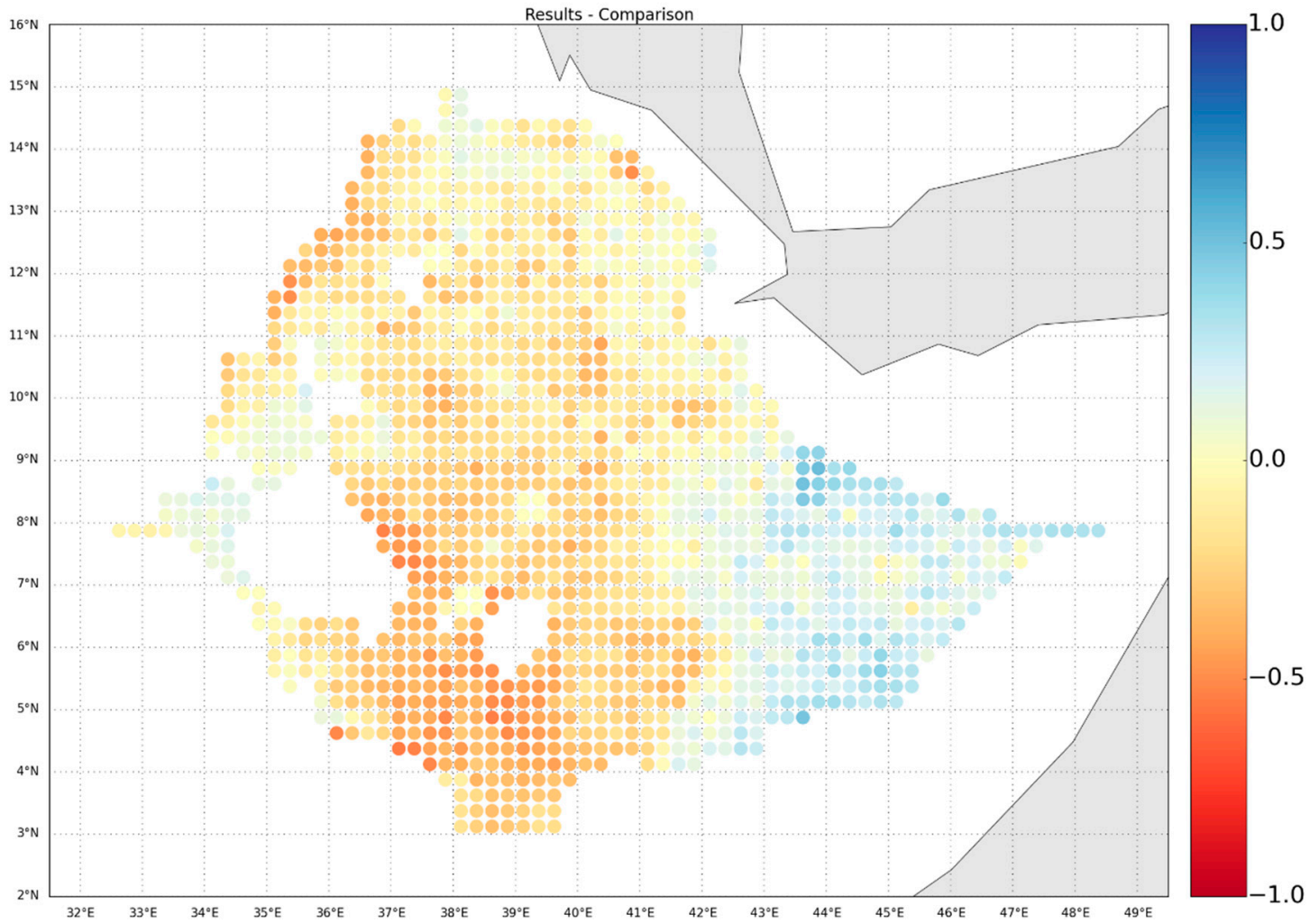

Figure 9. Comparison of ECDI warning levels and sc-PDSI for 1992-2012: average Pearson's R: -0.09, and average Stdv: 0.2. Regions with dense vegetation or complex topography and lakes are masked. 


\subsection{Ground Truthing}

This section concentrates on three steps of analysis. First, we focus on the analysis of the time series of all raw datasets and their corresponding anomalies. Second, we present the time series and the corresponding metrics of the ECDI warning levels, the scPDSI and the SPEI for two locations in the Tigray region. Third, we discuss the decadal ECDI warning levels for years in which SOS or EOS soil moisture deficits had been reported by farmers in the Tigray region $(2007,2013,2014$, and 2015) and for the widespread drought event in 2011 in Southern/Eastern Ethiopia.

\subsubsection{Analysis of Raw Data and Anomalies}

Figures S13 and S14 illustrate the time series of rainfall, soil moisture, land surface temperature and vegetation status for 2007 to mid 2015 as well as anomalies that were calculated based on each dataset's entire climatology. Figure S13 covers the cities of Atsbi and Kinte Awelo, respectively. In particular, the SOS/EOS deficit in 2007 and the SOS deficit in 2013 are well reflected in the soil moisture anomaly. None of the other variables clearly indicates a deficit. The NDVI anomaly even indicates a slight to strong positive anomaly for all four events. Figure S14 represents the conditions around the city of Saesi Daedsaemba. Due to the geographic proximity to the other two cities the anomalies indicate similar conditions. Again, there is no deficit visible in the anomalies of vegetation status and rainfall. However, a negative soil moisture anomaly is detected for both SOS and EOS in 2007. The 2013 event is even more pronounced with a negative anomaly starting in late 2012. For 2014 and 2015, we observe only very slight soil moisture deficits.

\subsubsection{Drought Index Performance Metrics}

This section concentrates on the time series analysis for the six regions of interest in Figure 10. All correlations (Pearson's correlation coefficient (R) and Spearman's correlation coefficient (S)) in Table 3 are calculated for the entire time series and for the Kiremit season, which is the wet summer season. As already indicated by the analysis on country-scale, the correlation coefficients are relatively low for all combinations. We observed the highest (negative) correlation $(R=-0.53$; bold number in Table 3) between the ECDI-based warning levels and the SPEI during the wet season in the south of the country along the Somali boarder. Restricting the calculation to the summer season does not result in a clear trend. In some cases, the correlation decreases (e.g., ECDI warning levels vs. SPEI in R1), while in other cases it increases (e.g., ECDI warning levels vs. SPEI in R3). For virtually all regions of interest the agreement of the ECDI warning levels and the SPEI is comparable or higher than when compared to the scPDSI. Figure 11 illustrates the time series of the three indices for region R1 in Figure 10. Possibly caused by more recent advances in data quality (e.g., due to new sensors), the correlation between the ECDI warning levels and the SPEI increases from $R=-0.38(\mathrm{~S}=-0.36)$ to $R=-0.48(S=-0.57)$ if only the years 2007 to 2015 are considered. In particular, the 2013 drought event is well reflected.

The moderate agreement between scPDSI and SPEI could be related to their suitability to detect droughts at different time scales. Zhao et al. [86] argue that the SPEI is suitable to detect both shortand long-term drought events, whereas the scPDSI is only suitable to monitor mid- to long-term drought events. Since contradictory signals from different drought indicators are problematic from a decision-making point of view, the following section deals with the direct comparison of the ECDI-based warning levels with actual impacts based on field reports. 
Table 3. Performance Metrics for the Tigray Region (WL = Warning Level, $R=$ Pearson's correlation coefficient, $\mathrm{S}=$ Spearman's correlation coefficient); The two Coordinates in Region 1 (R1) cover the cities of Atsbi and Kinte Awelo, while R2 covers the city of Saesi Daedsaemba.

\begin{tabular}{|c|c|c|c|c|c|c|c|}
\hline Region & $\begin{array}{l}\text { Drought } \\
\text { Index } 1\end{array}$ & $\begin{array}{l}\text { Drought } \\
\text { Index } 2\end{array}$ & Location & $\mathbf{R}$ & R (June-September) & $\mathbf{S}$ & S (June-September) \\
\hline $\mathrm{R} 1$ & scPDSI & SPEI & $\begin{array}{l}39.72 \mathrm{E} / 13.85 \mathrm{~N} \\
39.59 \mathrm{E} / 13.79 \mathrm{~N}\end{array}$ & 0.23 & 0.20 & 0.02 & 0.19 \\
\hline $\mathrm{R} 1$ & ECDI WL & scPDSI & $\begin{array}{l}39.72 \mathrm{E} / 13.85 \mathrm{~N} \\
39.59 \mathrm{E} / 13.79 \mathrm{~N}\end{array}$ & -0.06 & 0.12 & 0.08 & 0.32 \\
\hline R1 & ECDI WL & SPEI & $\begin{array}{l}39.72 \mathrm{E} / 13.85 \mathrm{~N} \\
39.59 \mathrm{E} / 13.79 \mathrm{~N}\end{array}$ & -0.38 & -0.30 & -0.43 & -0.36 \\
\hline $\mathrm{R} 2$ & scPDSI & SPEI & $39.56 \mathrm{E} / 14.1 \mathrm{~N}$ & 0.15 & 0.10 & 0.09 & 0.21 \\
\hline $\mathrm{R} 2$ & ECDI WL & scPDSI & $39.56 \mathrm{E} / 14.1 \mathrm{~N}$ & -0.21 & -0.08 & -0.23 & -0.14 \\
\hline $\mathrm{R} 2$ & ECDI WL & SPEI & $39.56 \mathrm{E} / 14.1 \mathrm{~N}$ & -0.16 & -0.19 & -0.25 & -0.23 \\
\hline R3 & scPDSI & SPEI & $39.5 \mathrm{E} / 4.00 \mathrm{~N}$ & 0.47 & 0.38 & 0.42 & 0.38 \\
\hline R3 & ECDI WL & scPDSI & $39.5 \mathrm{E} / 4.00 \mathrm{~N}$ & -0.45 & -0.44 & -0.46 & -0.40 \\
\hline R3 & ECDI WL & SPEI & $39.5 \mathrm{E} / 4.00 \mathrm{~N}$ & -0.41 & -0.53 & -0.43 & -0.45 \\
\hline $\mathrm{R} 4$ & scPDSI & SPEI & $42.75 \mathrm{E} / 4.75 \mathrm{~N}$ & 0.25 & 0.36 & 0.30 & 0.15 \\
\hline $\mathrm{R} 4$ & ECDI WL & scPDSI & $42.75 \mathrm{E} / 4.75 \mathrm{~N}$ & 0.23 & 0.42 & 0.26 & 0.47 \\
\hline $\mathrm{R} 4$ & ECDI WL & SPEI & $42.75 \mathrm{E} / 4.75 \mathrm{~N}$ & -0.44 & -0.32 & -0.26 & -0.30 \\
\hline R5 & scPDSI & SPEI & $46.0 \mathrm{E} / 6.5 \mathrm{~N}$ & 0.26 & 0.12 & 0.14 & -0.12 \\
\hline R5 & ECDI WL & scPDSI & $46.0 \mathrm{E} / 6.5 \mathrm{~N}$ & 0.01 & -0.16 & 0.10 & -0.11 \\
\hline R5 & ECDI WL & SPEI & $46.0 \mathrm{E} / 6.5 \mathrm{~N}$ & -0.18 & 0.05 & -0.07 & 0.01 \\
\hline R6 & scPDSI & SPEI & $41.5 \mathrm{E} / 7.5 \mathrm{~N}$ & 0.40 & 0.07 & 0.42 & 0.05 \\
\hline R6 & ECDI WL & scPDSI & $41.5 \mathrm{E} / 7.5 \mathrm{~N}$ & 0.0 & -0.06 & -0.02 & -0.04 \\
\hline R6 & ECDI WL & SPEI & $41.5 \mathrm{E} / 7.5 \mathrm{~N}$ & -0.34 & -0.35 & -0.37 & -0.42 \\
\hline
\end{tabular}

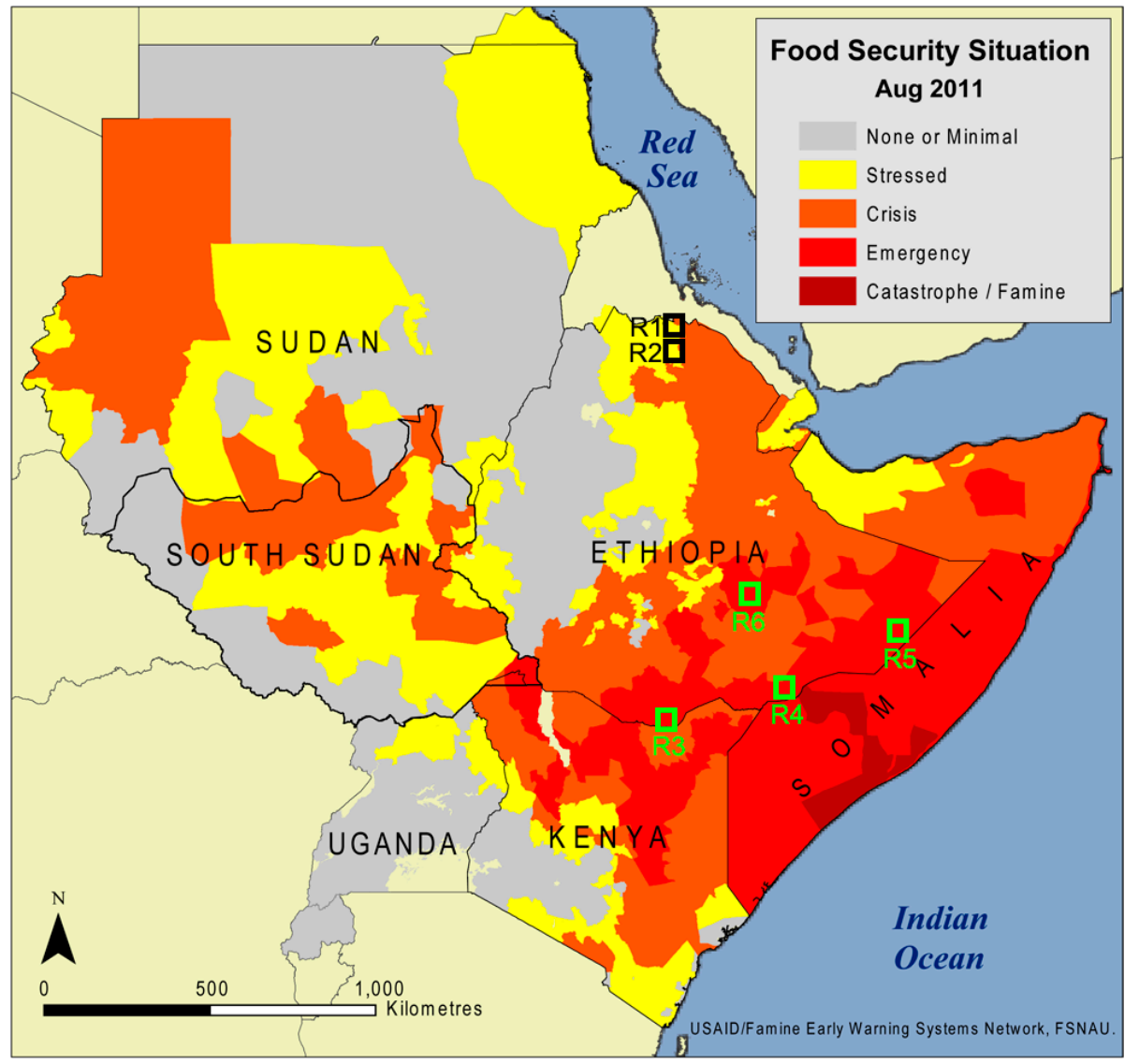

Figure 10. Food Security Situation 2011 according to US AID and the Famine Early Warning Systems network (FEWSNET). Regions of Interest (R) 1 and 2 are located in Tigray, while R3 to R6 are located in zones that were classified as "emergency" during the 2011 drought event. 


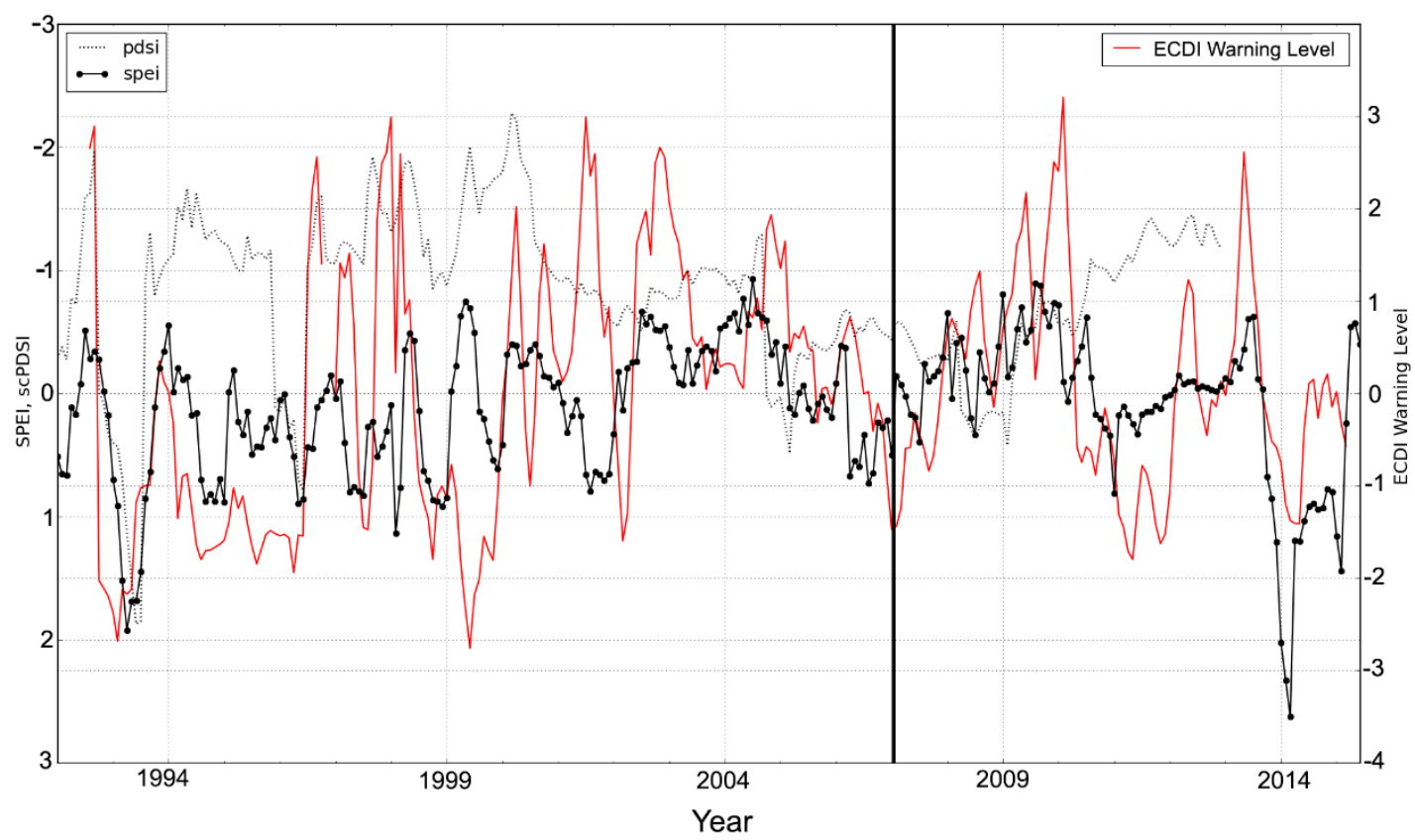

Figure 11. Time series of the ECDI Warning Levels, scPDSI and SPEI (Atbsi/Kinte Awelo region, Northern Ethiopia) for 1992-2015. The left y-axis (SPEI and scPDSI) was inverted for easier visual comparison. The correlation of the ECDI warning levels and the SPEI increases after 2007 (vertical black line).

\subsubsection{Analysis of Warning Levels}

Figure S15 to Figure S19 illustrate the ECDI-based drought warning levels from normal to extreme drought risk for 2007, 2011 and 2013-2015. In 2007 (Figure S15), we generally observe a relatively localized event. The ECDI warning levels indicate a first increase in drought risk early in February/March (decades 6-8) and a second increase in June, which lasted until the end of the wet season in decade 28 (early September). The 2011 event is triggered by an increased drought risk in late 2010 (not shown). Figure S16 shows severe to extreme conditions in the south and southeast of Ethiopia starting in January 2011. When the famine was officially declared in July 2011 the ECDI warning levels already start to shift towards mild drought conditions. The 2013 SOS deficit in Tigray is illustrated in Figure S17. The Tigray region is affected by an increased drought risk starting in January. Afterwards, the drought risk gradually expands and covers the entire north of the country by June. Note that, for instance, in the case of corn, a water deficit of ten percent during the tassling/silking stage can result in yield decrease of 25 percent [87]. Even late in 2013 Tigray is partly affected by high levels of drought risk. The drought conditions that affected Tigray early in the 2014 season (Figure S18) could be detected, but they are far less distinct than in 2007. By May 2014 the drought warning level increases for large parts of the country, but the ECDI warning levels only indicate severe to extreme conditions for a few disconnected regions in the north, south and central Ethiopia. The drought risk pattern of 2015 (Figure S19) is different, because it shows an increased drought risk in January that already starts to shift to normal conditions in February. Nevertheless, it is possible that a rainfall deficit led to a soil moisture deficit during the Belg season, which is usually characterized by occasional showers and the highest temperatures in May. However, our current record for the ECDI-based drought warning levels ends late March 2015.

In summary, the warning levels indicate an increased warning level for all reported drought events. However, for some cases (e.g., the 2014 event) the warning levels only rise for the duration of several decades, which highlights the importance of in-depth knowledge about local agricultural practices. An extreme warning level during the period that is normally used for sowing might have a larger impact than a severe warning level during a different, longer period. 


\subsection{Drought Forecasting}

The forecasting ECDI was calculated based on the framework presented in Figure 5 for all nine regional states in Ethiopia and for up to 21 decades. Figure 12 illustrates the performance of forecasted ECDI via Heidke-Skill-Score for four selection regions (Amhara, Tigray, Gambela and Oromia). In general, the forecasted ECDI tends to perform better for the lowest ECDI class (0-0.2) and the highest ECDI class (0.7-1) than for conditions closer to the "average". However, the forecasting skill decreases rapidly after 2-3 decades, indicating that the ECDI is currently not able to provide a seasonal forecast. Two potential reasons lie in the quality of the seasonal ensemble forecasts and the unsuitability of the linear CDF matching.
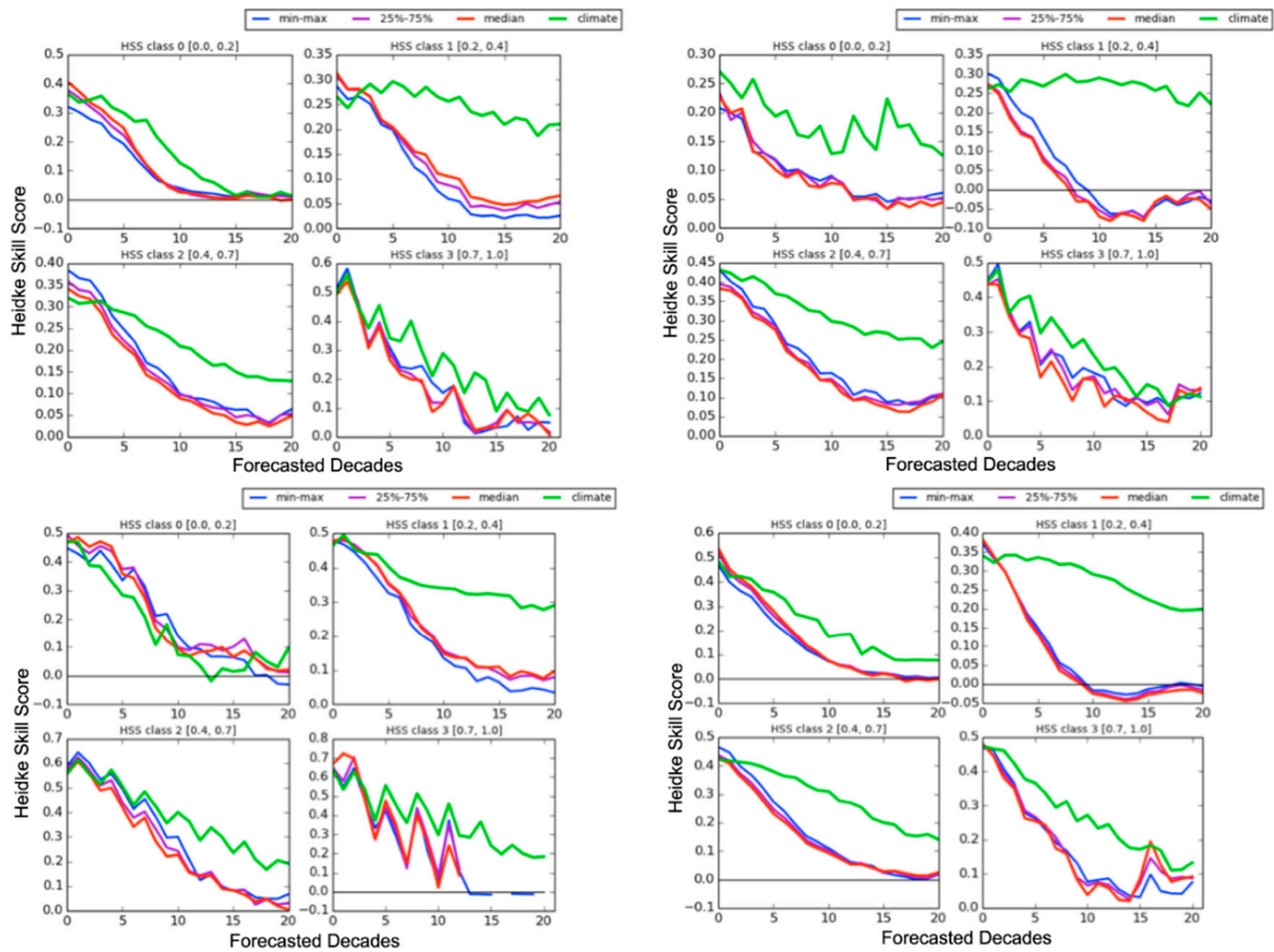

Figure 12. Heidke-Skill-Score (HSS) for the low (0-0.2), medium (0.2-0.4), high (0.4-0.7) and very high (0.7-1) ECDI values, corresponding to extreme, severe, increased and normal drought risk for: Afar (upper left); Tigray (upper right); Gambela (lower left); and Oromia (lower right). For every set of 15 ensemble members, the minimum, lower quantile (25\%), median, upper quantile $(75 \%)$ and maximum ECDI value are calculated for the 21 future decades. A HSS of 1 corresponds to the "perfect" forecast. For almost all classes, the climatology (green line) outperforms the forecasted ECDI after two to three decades at the maximum.

In addition, we analyzed the dependency of the forecasting bias with regard to seasonality (not shown). There is a clear seasonal trend in the forecasting ECDI, which indicates that the bias increases in the wet season. Forecasting runs starting in January tend to show an increased bias towards the end of the 21 decades (the wet season). In contrast, forecasting runs starting in May show a higher bias at the beginning of the 21 decades that gradually decreases. 


\section{Conclusions and Outlook}

This study is part of a framework that aims to provide user-specific information for humanitarian aid organizations, such as MSF, with respect to advanced drought and food security monitoring. We focus on the algorithmic development and validation of a new drought indicator that combines space-based observations of four key variables over Ethiopia. The other two components of the framework concentrate on the coupling between socio-economic and satellite-derived information via a mobile app and on identifying the added-value of seasonal forecasts.

With regard to the new ECDI, the main improvement lies in the replacement of in-situ measurements, which are very limited in large regions of Africa, with satellite-derived datasets. In addition to widely used rainfall, land surface temperature and vegetation status we introduce a satellite-derived soil moisture component, which the original CDI and most other drought indices are lacking. All input datasets are resampled to a spatial resolution of $0.25^{\circ}$ (roughly $28 \mathrm{~km}$ ) and averaged at decadal (10-daily) time steps. With sufficient processing power the spatial resolution can be increased to exploit for instance the higher resolution of the vegetation datasets, if the spatio-temporal relationships between all input variables are known. Furthermore, we present a method to distribute the weight of each of the four input datasets for each grid point individually. The weight is automatically redistributed if gaps in any input dataset are detected. Based on a new toolbox named POETS a web-platform allows to display time series and images of all datasets (raw data, climatology-based anomalies, individual drought indices for every variable and the ECDI).

According to the frequency distribution of the ECDI-based warning levels in Ethiopia, we observe plausible distributions: no drought conditions during 71 percent of the time between 1992 and 2015, while 22 percent of the time the warning levels indicate a "mild drought risk", six percent a "severe drought risk" and less than one percent an "extreme drought risk". Ranking the years based on the frequency of each drought warning level for all grid points facilitates the identification of most events that affected large parts of the country (e.g., 2002/2003, 2008/2009, 2011/2012). In this context, we highlight the importance of continuous monitoring. Increased drought levels over long periods might lead to a crisis in a subsequent year that is characterized by lower warning levels. In contrast, a low warning level can also result in negative socio-economic consequences for the following year. Surplus production can lead to a decline in agricultural prices in the same or the subsequent year up to a level that does not allow farmers to cover their production costs [88].

The ECDI and its warning levels outperform the Standardized Precipitation Evapotranspiration Index (SPEI) and the weather station data-based self-calibrated Palmer Drought Severity Index (scPDSI) regarding spatial and temporal resolution. However, our results indicate a low overall agreement between all drought indicators on country level (Figures 7 and 8). In general, the ECDI warning levels show a higher agreement with the SPEI than with the scPDSI. In particular, when focusing on the Belg season, the main rainy season for agricultural production in the east and south, we observe higher negative correlations $(R=-0.31)$ than in the main rainy season (Table 2). With regard to our six regions of interest we observe the highest overall correlation $(R=-53$; Table 3) between the ECDI warning levels and the SPEI for a region in the south of Ethiopia. The negative correlation can be interpreted as an agreement due to the inverse relationship of the ECDI-based warning levels and the other two drought indices. Since contradictory signals of different drought indicators cause complications to decision-makers, we also compare the ECDI warning levels to field reports from the Tigray region and to the well-documented 2011 drought event. However, future studies will need to analyze the agreement of the ECDI with other drought indices at different time scales to distinguish differences caused by the selection of the input data from methodical differences.

The ECDI-based warning levels (Figures S15-S19) manage relatively well to reflect all SOS and EOS deficits that had been reported by farmers in the Northern Tigray region between 2007 and 2015. With regard to the severe drought event in 2011 a high warning level is already indicated in January. However, the famine had only been officially declared in July 2011. Limited by data availability during the production of this study, we can only observe a shift from severe to mild drought conditions 
from January to March 2015. We generally recommend the consideration of ECDI warning levels in combination with short-term anomalies. Figures S13 and S14 compare the climatology-based anomalies of rainfall, soil moisture, land surface temperature and vegetation status to the drought reports of Ethiopian farmers in the Tigray region. With regard to the detection of anomalous conditions, the SOS or EOS satellite-derived soil moisture matches the reported drought conditions more closely than the anomalies of rainfall, land surface temperature or vegetation health.

Future improvements of the ECDI will focus on the forecasting ECDI and the weight distribution. The forecasting ECDI's skill to predict agricultural drought conditions is currently limited to a few decades (Section 4.4). Potential improvements should focus on testing alternatives to the linear CDF matching technique. The weight distribution is currently based on the correlation of rainfall, soil moisture and land surface temperature with the vegetation status and the corresponding time lag. However, this method is not optimized for regions that are characterized by low NDVI values (e.g., <0.2), which usually represent bare soils. Applying a mask for these areas and for regions in which irrigation distorts the soil moisture signal could be a first solution. The use of crop-specific masks to focus on staple crops, such as grains, sorghum or pulses is also possible. Another advancement could be the replacement of the NDVI component with actual or predicted yield data, such as provided by the Vegetation Outlook (VegOut) for Ethiopia [57]. All datasets needed to run an empirical regression model are already available via POETS. Therefore, it might be useful to merge the MODIS NDVI product with the GIMMS (Global Inventory Modeling and Mapping Studies) dataset [89]. The presented method to run the ECDI on seasonal ensemble forecasts also needs to be evaluated via hindcast analysis to identify which degree of uncertainty is acceptable to decision-makers. Since the calibration of the forecasted ECDI depends on the quality of the monitoring ECDI it could be beneficial to extend POETS via new products, such as the higher resolution soil moisture observations from Sentinel-1 or SMAP (Soil Moisture Active Passive).

Despite possible improvements, the current version of the ECDI-based warning levels is already able to reflect most reported drought conditions in Ethiopia timely and reliably. However, we also observed high warning levels for periods that did not seem to have a strong impact on people's livelihoods or agricultural production. Hence, we conclude that a user-tailored monitoring system needs to exploit different sources of information about environmental anomalies in combination with assessments of additional socio-economic vulnerabilities and coping capacities. Without in-depth retrospective studies about the potential of drought indicators to reflect actual conditions on the ground it will not be possible to match the severity represented by a drought index to the magnitude of the actual event. However, if these studies are carried out successfully, satellite-derived drought indicators have the potential to serve as an additional basis for the decision-support of aid organizations instead of just confirming existing knowledge.

Supplementary Materials: The following are available online at www.mdpi.com/2072-4292/8/4/340/s1. Table S1: Input Variables for the Enhanced Combined Drought Index; Figure S13: Time series for all raw data and corresponding anomalies that are currently processed by POETS; The time series cover 2007 to mid 2015 for the regions of Atsbi and Kinte Awelo; Report drought conditions are highlighted in green; Figure S14: Time series for all raw data and corresponding anomalies that are currently processed by POETS; The time series cover 2007 to mid 2015 for the region of Saesi Daesdaemba; Report drought conditions are highlighted in green; Figure S15: ECDI-based Drought Risk Level for all decades of 2007; Maximum warning level: 3.4 (decade 1); Figure S16: ECDI-based Drought Risk Level for the first 21 decades (seven months) of 2011; July is included, because famine was officially declared on 20 July; Maximum warning level: 3.5 (decade 20, 10-20 July 2011); Figure S17: ECDI-based Drought Risk Level for all decades of 2013; Maximum warning level 3.5 (decades 3-6, late January to late February 2013); Figure S18: ECDI-based Drought Risk Level for the first 18 decades (six months) of 2014; Maximum warning level: 2.9 (decade 1 and 3-6, early January and late January to late February); Figure S19: ECDI-based Drought Risk Level for the first 9 decades (three months) of 2015; Maximum warning level: 3.5 (decades 7 and 9, early and late March).

Acknowledgments: This research was supported and funded in the framework of SATIDA (Satellite Technologies for Improved Drought-Risk Assessment). SATIDA is a project within the Austrian Space Applications Programme (ASAP10) of the Austrian Research Promotion Agency (project number 4277353). 
Author Contributions: M.E. designed the overall methodical framework for the development and validation of the ECDI, carried out large parts of the algorithmic implementation and wrote the manuscript in large part. C.S. supported the manuscript with regard to the algorithmic development and data analysis. W.D. and W.W. supported the manuscript with regard to the algorithmic development of the ECDI and its validation. T.M. supported the manuscript via algorithmic implementations. L.S. supported the manuscript with regard to the validation of the ECDI via the SPEI/scPDSI. C.A. supported the algorithmic development of the ECDI with regard to the vegetation status. S.S. supported the study with respect to seasonal predictions and the forecasted ECDI. E.D. supported the validation of the ECDI via the identification of warning levels with respect to drought impacts.

Conflicts of Interest: The authors declare no conflict of interest.

\section{References}

1. Belal, A.-A.; El-Ramady, H.R.; Mohamed, E.S.; Saleh, A.M. Drought risk assessment using remote sensing and GIS techniques. Arab. J. Geosci. 2012, 7, 35-53. [CrossRef]

2. Lloyd-Hughes, B. The impracticality of a universal drought definition. Theor. Appl. Climatol. 2014, 117, 607-611. [CrossRef]

3. Overseas Development Institute Poverty and Poverty Reduction in Sub-Saharan Africa: An Overview of the Issues. Available online: http://www.odi.org/sites/odi.org.uk/files/odi-assets/publicationsopinion-files/860.pdf (accessed on 14 October 2015).

4. UN Food and Agriculture Organization. The State of Food Insecurity in the World-Meeting the 2015 International Hunger Targets: Taking Stock of Uneven Progress; UN Food and Agriculture Organization: Rome, Italy, 2015.

5. UN Food and Agriculture Organization of the United Nations. The State of Food Insecurity in the World. High Food Prices and Food Security—Threats and Opportunities; UN Food and Agriculture Organization: Rome, Italy, 2008.

6. Brown, M.E.; Funk, C.C. Food security under climate change. Science 2008, 319, 580-581. [CrossRef] [PubMed]

7. Funk, C.C.; Brown, M.E. Declining global per capita agricultural production and warming oceans threaten food security. Food Secur. 2009, 1, 271-289. [CrossRef]

8. United Nations Office for Disaster Risk Reduction (UNISDR). United Nations General Assembly Sendai Framework for Disaster Risk Reduction 2015-2030. In Proceedings of the Third United Nations World Conference on Disaster Risk Reduction, Sendai, Japan, 14-18 March 2015.

9. Space-based Information for Disaster-Risk Reduction. Available online: http://www.un-spider.org/sites / default/files/Two_Pager_WCDRR_0.pdf (accessed on 22 June 2015).

10. Verdin, J.; Funk, C.; Senay, G.; Choularton, R. Climate science and famine early warning. Philos. Trans. R. Soc. Lond. B Biol. Sci. 2005, 360, 2155-2168. [CrossRef] [PubMed]

11. Rashid, A. Global Information and Early Warning System on Food and Agriculture: Appropriate Technology and Institutional Development Challenges. In Early Warning Systems for Natural Disaster Reduction; Zschau, P.D.J., Küppers, A., Eds.; Springer Berlin Heidelberg: Berlin, Germany; Heidelberg, Germany, 2003; pp. 337-344.

12. Sheffield, J.; Wood, E.F.; Chaney, N.; Guan, K.; Sadri, S.; Yuan, X.; Olang, L.; Amani, A.; Ali, A.; Demuth, S.; et al. A Drought Monitoring and Forecasting System for Sub-Sahara African Water Resources and Food Security. Bull. Am. Meteorol. Soc. 2014, 95, 861-882. [CrossRef]

13. Brown, M. Famine Early Warning Systems and Remote Sensing Data; Springer Berlin Heidelberg: Berlin, Germany; Heidelberg, Germany, 2008.

14. Coughlan de Perez, E.; van den Hurk, B.; van Aalst, M.; Jongman, B.; Klose, T.; Suarez, P. Forecast-based financing: An approach for catalyzing humanitarian action based on extreme weather and climate forecasts. Nat. Hazards Earth Syst. Sci. Discuss 2014, 2, 3193-3218. [CrossRef]

15. Kull, D.; Mechler, R.; Hochrainer-Stigler, S. Probabilistic cost-benefit analysis of disaster risk management in a development context. Disasters 2013, 37, 374-400. [CrossRef] [PubMed]

16. Kellett, J.; Caravani, A. Financing Disaster Risk Reduction-A 20 Year Story of International Aid. Available online: http://www.odi.org/sites/odi.org.uk/files/odi-assets/publications-opinion-files/8574.pdf (accessed on 14 October 2015).

17. Bachmair, S.; Kohn, I.; Stahl, K. Exploring the link between drought indicators and impacts. Nat. Hazards Earth Syst. Sci. 2015, 15, 1381-1397. [CrossRef] 
18. Wilhite, D.A.; Svoboda, M.D.; Hayes, M.J. Understanding the complex impacts of drought: A key to enhancing drought mitigation and preparedness. Water Resour. Manag. 2007, 21, 763-774. [CrossRef]

19. United Nations Statistics Division UN Data Country Profiles 2014. Available online: http://data. un.org/CountryProfile.aspx (accessed on 14 October 2015).

20. US Agency for International Development Ethiopia Agriculture and Food Security 2015. Available online: https:/ / www.usaid.gov/ethiopia/agriculture-and-food-security (accessed on 14 October 2015).

21. Peel, M.C.; Finlayson, B.L.; McMahon, T.A. Updated world map of the Köppen-Geiger climate classification. Hydrol. Earth Syst. Sci. 2007, 11, 1633-1644. [CrossRef]

22. Alliance Development Works and United Nations University. World Risk Report 2014; Alliance Development Works: Berlin, Germany; United Nations University: Bonn, Germany, 2014.

23. Naumann, G.; Barbosa, P.; Garrote, L.; Iglesias, A.; Vogt, J. Exploring drought vulnerability in Africa: An indicator based analysis to be used in early warning systems. Hydrol. Earth Syst. Sci. 2014, 18, 1591-1604. [CrossRef]

24. Funk, C.; Dettinger, M.D.; Michaelsen, J.C.; Verdin, J.P.; Brown, M.E.; Barlow, M.; Hoell, A. Warming of the Indian Ocean threatens eastern and southern African food security but could be mitigated by agricultural development. Proc. Natl. Acad. Sci. USA 2008, 105, 11081-11086. [CrossRef] [PubMed]

25. Clay, J.W.; Holcomb, B.K. Politics and the Ethiopian Famine: 1984-1985; Transaction Publishers: Cambridge, MA, USA, 1985.

26. Hillbruner, C.; Moloney, G. When early warning is not enough—Lessons learned from the 2011 Somalia Famine. Glob. Food Secur. 2012, 1, 20-28. [CrossRef]

27. Funk, C. We thought trouble was coming. Nat. News 2011, 476. [CrossRef] [PubMed]

28. Maidment, R.I.; Grimes, D.; Allan, R.P.; Tarnavsky, E.; Stringer, M.; Hewison, T.; Roebeling, R.; Black, E. The 30 year TAMSAT African Rainfall Climatology and Time series (TARCAT) data set. J. Geophys. Res. Atmos. 2014, 119. [CrossRef]

29. Tarnavsky, E.; Grimes, D.; Maidment, R.; Black, E.; Allan, R.P.; Stringer, M.; Chadwick, R.; Kayitakire, F. Extension of the TAMSAT Satellite-Based Rainfall Monitoring over Africa and from 1983 to Present. J. Appl. Meteorol. Climatol. 2014, 53, 2805-2822. [CrossRef]

30. Wan, Z. New refinements and validation of the MODIS Land-Surface Temperature/Emissivity products. Remote Sens. Environ. 2008, 112, 59-74. [CrossRef]

31. Balint, Z.; Mutua, F.M.; Muchiri, P. Drought Monitoring with the Combined Drought Index; FAO-SWALIM: Nairobi, Kenya, 2011.

32. Palmer, W.C. Meteorological Drought; US Department of Commerce: Washington, DC, USA, 1965.

33. Wells, N.; Goddard, S.; Hayes, M.J. A Self-Calibrating Palmer Drought Severity Index. J. Clim. 2004, 17, 2335-2351. [CrossRef]

34. Vicente-Serrano, S.M.; Beguería, S.; López-Moreno, J.I. A Multiscalar Drought Index Sensitive to Global Warming: The Standardized Precipitation Evapotranspiration Index. J. Clim. 2010, 23, 1696-1718. [CrossRef]

35. AghaKouchak, A. A baseline probabilistic drought forecasting framework using Standardized Soil Moisture Index: Application to the 2012 United States drought. Hydrol. Earth Syst. Sci. 2014, 18, 2485-2492. [CrossRef]

36. Qiu, J.; Crow, W.T.; Nearing, G.S.; Mo, X.; Liu, S. The impact of vertical measurement depth on the information content of soil moisture times series data. Geophys. Res. Lett. 2014. [CrossRef]

37. El Sharif, H.; Wang, J.; Georgakakos, A.P. Modeling Regional Crop Yield and Irrigation Demand Using SMAP Type of Soil Moisture Data. J. Hydrometeorol. 2015, 16, 904-916. [CrossRef]

38. Kumar, S.V.; Harrison, K.W.; Peters-Lidard, C.D.; Santanello, J.A.; Kirschbaum, D. Assessing the Impact of L-Band Observations on Drought and Flood Risk Estimation: A Decision-Theoretic Approach in an OSSE Environment. J. Hydrometeorol. 2014, 15, 2140-2156. [CrossRef]

39. McKee, T.B.; Doesken, N.J.; Kleist, J. The Relationship of Drought Frequency and Duration to time Scales. In Proceedings of the Eighth Conference on Applied Climatology, Anaheim, CA, USA, 17-22 January 1993.

40. Tucker, C.J. Red and photographic infrared linear combinations for monitoring vegetation. Remote Sens. Environ. 1979, 8, 127-150. [CrossRef]

41. Dai, A. Characteristics and trends in various forms of the Palmer Drought Severity Index during 1900-2008. J. Geophys. Res. 2011, 116. [CrossRef] 
42. Otkin, J.A.; Anderson, M.C.; Hain, C.; Mladenova, I.E.; Basara, J.B.; Svoboda, M. Examining Rapid Onset Drought Development Using the Thermal Infrared-Based Evaporative Stress Index. J. Hydrometeorol. 2013, 14, 1057-1074. [CrossRef]

43. Anderson, M.C.; Zolin, C.A.; Sentelhas, P.C.; Hain, C.R.; Semmens, K.; Tugrul Yilmaz, M.; Gao, F.; Otkin, J.A.; Tetrault, R. The Evaporative Stress Index as an indicator of agricultural drought in Brazil: An assessment based on crop yield impacts. Remote Sens. Environ. 2016, 174, 82-99. [CrossRef]

44. Dinku, T.; Ceccato, P.; Grover-Kopec, E.; Lemma, M.; Connor, S.J.; Ropelewski, C.F. Validation of satellite rainfall products over East Africa's complex topography. Int. J. Remote Sens. 2007, 28, 1503-1526. [CrossRef]

45. Thiemig, V.; Rojas, R.; Zambrano-Bigiarini, M.; Levizzani, V.; De Roo, A. Validation of Satellite-Based Precipitation Products over Sparsely Gauged African River Basins. J. Hydrometeorol. 2012, 13, 1760-1783. [CrossRef]

46. The World Bank Turn down the Heat. Why a $4{ }^{\circ} \mathrm{C}$ Warmer World Must Be Avoided; The World Bank: Washington, DC, USA, 2012.

47. Liu, Y.Y.; Dorigo, W.A.; Parinussa, R.M.; de Jeu, R.A.M.; Wagner, W.; McCabe, M.F.; Evans, J.P.; van Dijk, A.I.J.M. Trend-preserving blending of passive and active microwave soil moisture retrievals. Remote Sens. Environ. 2012, 123, 280-297. [CrossRef]

48. Liu, Y.; Parinussa, R.M.; Dorigo, W.A.; De Jeu, R.A.M.; Wagner, W.; van Dijk, A.I.J.M.; McCabe, M.F.; Evans, J.P. Developing an improved soil moisture dataset by blending passive and active microwave satellite-based retrievals. Hydrol. Earth Syst. Sci. 2011, 15, 425-436. [CrossRef]

49. Wagner, W.; Dorigo, W.; De Jeu, R.A.M.; Fernandez, D.; Benveniste, J.; Haas, E.; Ertl, M. Fusion of Active and Passive Microwave Observations to create an Essential Climate Variable Data Record on Soil Moisture. In ISPRS Annals of the Photogrammetry, Remote Sensing and Spatial Information Sciences; ISPRS: Melbourne, Australia, 2012; Volume I-7.

50. McNally, A.; Shukla, S.; Arsenault, K.R.; Wang, S.; Peters-Lidard, C.D.; Verdin, J.P. Evaluating ESA CCI soil moisture in East Africa. Int. J. Appl. Earth Obs. Geoinf. 2016, 48, 96-109. [CrossRef]

51. Li, X.; Zhang, L.; Weihermuller, L.; Jiang, L.; Vereecken, H. Measurement and Simulation of Topographic Effects on Passive Microwave Remote Sensing Over Mountain Areas: A Case Study From the Tibetan Plateau. IEEE Trans. Geosci. Remote Sens. 2014, 52, 1489-1501. [CrossRef]

52. Wagner, W.; Hahn, S.; Kidd, R.; Melzer, T.; Bartalis, Z.; Hasenauer, S.; Figa-Saldaña, J.; de Rosnay, P.; Jann, A.; Schneider, S.; et al. The ASCAT Soil Moisture Product: A Review of its Specifications, Validation Results, and Emerging Applications. Meteorol. Z. 2013, 22, 5-33. [CrossRef]

53. Anyamba, A.; Tucker, C.J. Analysis of Sahelian vegetation dynamics using NOAA-AVHRR NDVI data from 1981-2003. J. Arid Environ. 2005, 63, 596-614. [CrossRef]

54. Rembold, F.; Atzberger, C.; Savin, I.; Rojas, O. Using Low Resolution Satellite Imagery for Yield Prediction and Yield Anomaly Detection. Remote Sens. 2013, 5, 1704-1733. [CrossRef]

55. Atzberger, C. Advances in Remote Sensing of Agriculture: Context Description, Existing Operational Monitoring Systems and Major Information Needs. Remote Sens. 2013, 5, 949-981. [CrossRef]

56. De Leeuw, J.; Vrieling, A.; Shee, A.; Atzberger, C.; Hadgu, K.M.; Biradar, C.M.; Keah, H.; Turvey, C. The Potential and Uptake of Remote Sensing in Insurance: A Review. Remote Sens. 2014, 6, 10888-10912. [CrossRef]

57. Tadesse, T.; Demisse, G.B.; Zaitchik, B.; Dinku, T. Satellite-based hybrid drought monitoring tool for prediction of vegetation condition in Eastern Africa: A case study for Ethiopia. Water Resour. Res. 2014, 50, 2176-2190. [CrossRef]

58. Nicholson, S.E.; Davenport, M.L.; Malo, A.R. A comparison of the vegetation response to rainfall in the Sahel and East Africa, using normalized difference vegetation index from NOAA AVHRR. Clim. Chang. 1990, 17, 209-241. [CrossRef]

59. Herrmann, S.M.; Anyamba, A.; Tucker, C.J. Recent trends in vegetation dynamics in the African Sahel and their relationship to climate. Glob. Environ. Chang. 2005, 15, 394-404. [CrossRef]

60. D'Odorico, P.; Caylor, K.; Okin, G.S.; Scanlon, T.M. On soil moisture-vegetation feedbacks and their possible effects on the dynamics of dryland ecosystems. J. Geophys. Res. Biogeosci. 2007, 112. [CrossRef]

61. Jamali, S. Investigating Temporal Relationships between Rainfall, Soil Moisture and MODIS-Derived NDVI and EVI for Six Sites in Africa. Available online: http://www.isprs.org/proceedings/2011/ ISRSE-34/211104015Final00443.pdf (accessed on 14 October 2015). 
62. Wang, J.; Rich, P.M.; Price, K.P. Temporal responses of NDVI to precipitation and temperature in the central Great Plains, USA. Int. J. Remote Sens. 2003, 24, 2345-2364. [CrossRef]

63. Schnur, M.T.; Xie, H.; Wang, X. Estimating root zone soil moisture at distant sites using MODIS NDVI and EVI in a semi-arid region of southwestern USA. Ecol. Inform. 2010, 5, 400-409. [CrossRef]

64. Ji, L.; Peters, A.J. Lag and seasonality considerations in evaluating AVHRR NDVI response to precipitation. Photogramm. Eng. Remote Sens. 2005, 71, 1053-1061. [CrossRef]

65. Nandintsetseg, B.; Shinoda, M.; Kimura, R.; Ibaraki, Y. Relationship between Soil Moisture and Vegetation Activity in the Mongolian Steppe. Sci. Online Lett. Atmos. SOLA 2010, 6, 29-32. [CrossRef]

66. Zribi, M.; Paris Anguela, T.; Duchemin, B.; Lili, Z.; Wagner, W.; Hasenauer, S.; Chehbouni, A. Relationship between soil moisture and vegetation in the Kairouan plain region of Tunisia using low spatial resolution satellite data. Water Resour. Res. 2010, 46, 823-835. [CrossRef]

67. Atkinson, P.M.; Jeganathan, C.; Dash, J.; Atzberger, C. Inter-comparison of four models for smoothing satellite sensor time-series data to estimate vegetation phenology. Remote Sens. Environ. 2012, 123, 400-417. [CrossRef]

68. Rembold, F.; Meroni, M.; Urbano, F.; Royer, A.; Atzberger, C.; Lemoine, G.; Eerens, H.; Haesen, D. Remote sensing time series analysis for crop monitoring with the SPIRITS software: New functionalities and use examples. Environ. Inform. 2015, 3, 1-11. [CrossRef]

69. Atzberger, C.; Eilers, P.H.C. A time series for monitoring vegetation activity and phenology at 10-daily time steps covering large parts of South America. Int. J. Digit. Earth 2011, 4, 365-386. [CrossRef]

70. Eilers, P.H.C. A Perfect Smoother. Anal. Chem. 2003, 75, 3631-3636. [CrossRef] [PubMed]

71. Klisch, A.; Atzberger, C.; Luminari, L. Satellite-based drought monitoring in Kenya in an operational setting. ISPRS Int. Arch. Photogramm. Remote Sens. Spat. Inf. Sci. 2015, XL-7/W3, 433-439. [CrossRef]

72. Vuolo, F.; Mattiuzzi, M.; Klisch, A.; Atzberger, C. Data Service Platform for MODIS Vegetation Indices Time Series Processing at BOKU Vienna: Current Status and Future Perspectives; Michel, U., Civco, D.L., Ehlers, M., Schulz, K., Nikolakopoulos, K.G., Habib, S., Messinger, D., Maltese, A., Eds.; SPIE: Vienna, Austria, 2012.

73. Atzberger, C.; Eilers, P.H.C. Evaluating the effectiveness of smoothing algorithms in the absence of ground reference measurements. Int. J. Remote Sens. 2011, 32, 3689-3709. [CrossRef]

74. Klisch, A.; Atzberger, C. Operational Drought Monitoring in Kenya Using MODIS NDVI Time Series. Remote Sens. 2016, 8. [CrossRef]

75. Mistelbauer, T.; Enenkel, M.; Wagner, W. POETS-Python Open Earth Observation Tools, Poster: GIScience 2014. Available online: http://pub-geo.tuwien.ac.at/showentry.php?ID=231873\&lang=6\&nohtml=1 (accessed on 14 October 2015).

76. Balint, Z.; Mutua, F.; Muchiri, P.; Omuto, C.T. Monitoring Drought with the Combined Drought Index in Kenya. In Developments in Earth Surface Processes; Elsevier B.V.: Amsterdam, The Netherlands, 2013; Volume 16, pp. 341-356.

77. Berhan, G.; Tadesse, T.; Atnafu, S.; Hill, S. Drought Monitoring in Food-Insecure Areas of Ethiopia by Using Satellite Technologies. In Experiences of Climate Change Adaptation in Africa; Leal Filho, W., Ed.; Springer Berlin Heidelberg: Berlin, Germany; Heidelberg, Germany, 2011; pp. 183-200.

78. UK Met Office How to Use Our Long-Range Predictions. Available online: http://www.metoffice.gov.uk/ research/climate/seasonal-to-decadal/long-range/user-guide (accessed on 31 July 2014).

79. Molteni, F.; Stockdale, T.; Balmaseda, M.; Balsamo, G.; Buizza, R.; Ferranti, L.; Magnusson, L.; Mogensen, K.; Palmer, T.; Vitard, F. The New ECMWF Seasonal Forecasting System (System 4). In ECMWF Technical Memorandum (Technical Report), No. 656; European Centre for Medium-Range Weather Forecasts: Reading, UK, 2011.

80. Gneiting, T. Calibration of Medium-Range Weather Forecasts, ECMWF Technical Memorandum; European Centre for Medium-Range Weather Forecasts: Reading, UK, 2014; Volume 719.

81. Reliefweb Ethiopia Drought Fact Sheet \#1 (FY200). Available online: http://reliefweb.int/report/ ethiopia/ethiopia-drought-fact-sheet-1-fy-2000 (accessed on 14 October 2015).

82. UN Food and Agriculture Organization. Special Report FAO/FWP Crop and Food Supply Assessment Mission to Ethiopia 2001. Available online: http://www.fao.org/docrep/004/x9320e/x9320e00.HTM (accessed on 14 October 2015). 
83. UN Food and Agriculture Organization Ethiopia. Drought-Hit Farmers Receive Emergency Aid-Pre-Famine Conditions in Pockets of the Country, 2003. Available online: http://www.fao.org/ english/newsroom/news/2003/18548-en.html (accessed on 5 May 2015).

84. Meze-Hausken, E. Contrasting climate variability and meteorological drought with perceived drought and climate change in northern Ethiopia. Clim. Res. 2004, 27, 19-31. [CrossRef]

85. UN Food and Agriculture Organization Ethiopia. El Niño-Southern Oscillation (ENSO) and the Main Kiremt Rainy Season-An Assessment Using FAO's Agriculture Stress Index System (ASIS); UN Food and Agriculture Organization Ethiopia: Bole Subcity, Ethiopia, 2014.

86. Zhao, H.; Gao, G.; An, W.; Zou, X.; Li, H.; Hou, M. Timescale differences between SC-PDSI and SPEI for drought monitoring in China. Phys. Chem. Earth Parts ABC 2015, in press. [CrossRef]

87. Hane, D.C.; Pumphrey, F.V. Crop Water Use Curves for Irrigation Scheduling; Agricultural Experiment, Station, Oregon State University: Corvallis, OR, USA, 1984.

88. UN Emergencies Unit for Ethiopia. Livelihood disruption in cash crop and surplus producing areas-A situation analysis July 2002. Available online: http://reliefweb.int/sites/reliefweb.int/files/ resources/FD6A0E2619E3ECBD85256C0C00642F45-undpeue-eth-31jul.pdf (accessed on 14 October 2015).

89. Tucker, C.; Pinzon, J.; Brown, M.; Slayback, D.; Pak, E.; Mahoney, R.; Vermote, E.; El Saleous, N. An extended AVHRR 8-km NDVI dataset compatible with MODIS and SPOT vegetation NDVI data. Int. J. Remote Sens. 2005, 26, 4485-4498. [CrossRef]

(C) 2016 by the authors; licensee MDPI, Basel, Switzerland. This article is an open access article distributed under the terms and conditions of the Creative Commons Attribution (CC-BY) license (http:/ / creativecommons.org/licenses/by/4.0/). 